\title{
表界面化学调控二维材料电催化生物质转化的研究进展
}

\author{
王文涁温群磊刘友文* 翟天佑* \\ (华中科技大学 材料科学与工程学院 材料成形与模具技术国家重点实验室 武汉 430074)
}

\begin{abstract}
摘要 电催化生物质转化是以间歇式能源产生的电能驱动生物质电转化为高附加值有机化学品的过程, 将其与水分解 耦合能够产生高纯度氢气, 具有有效降低化石燃料消耗、优化能源结构及解决环境问题的潜力. 然而, 由于生物质具有 多个官能团及其转化反应涉及多个电子参与, 电催化生物质转化面临着转化效率低、选择性差和稳定性不足等挑战. 通过调控表面本征结构、构筑表面空位、引入表面杂原子和构建表面协同界面等一系列表界面化学工程对二维电催化 材料进行设计和改性, 实现对其表面电子结构和几何结构的优化, 可以有效地改善二维材料的电转化效率、选择性和 稳定性. 本综述详细介绍了表界面化学改性二维材料电催化生物质转化的最新研究进展, 总结了该研究领域存在的问 题, 并展望了其研究前景.
\end{abstract}

关键词 电催化生物质转化; 表界面化学; 二维材料; 高附加值有机化学品; 氢气

\section{Research Progress of Surface and Interface Chemistry Regulate Two-dimensional Materials for Electrocatalytic Biomass Conversion}

\author{
Wang, Wenbin \\ Wen, Qunlei \\ Liu, Youwen* \\ Zhai, Tianyou* \\ (State Key Laboratory of Material Processing and Die \& Mould Technology, School of Materials Science and Engineering, \\ Huazhong University of Science and Technology, Wuhan 430074, China)
}

\begin{abstract}
Electrocatalytic biomass conversion, which utilizing the electrical energy generated by intermittent energy, drive biomass into high value-added organic chemicals, and usually can be coupled with water splitting for the production of high-purity hydrogen. It has the potential to significantly decrease fossil fuel consumption, optimize energy structure and solve environmental issues. However, because biomass possess multiple groups and its conversion involves multiple electrons, electrocatalytic biomass conversion suffer from low conversion efficiency, bad selectivity and poor stability. Surface and interface chemistry engineering, such as regulating intrinsic structure, generating vacancies, introducing heteroatom, and constructing synergistic interface, can design and modify two-dimensional electrocatalysts to optimize their electronic structure and geometric structure, and effectively improve the electrocatalytic efficiency, selectivity and stability. This review provides an overview of recent advances about the role of surface and interface chemistry played on electrocatalytic biomass conversion of two-dimensional materials. In addition, the authors also give some perspectives on the challenges and prospects in this field.
\end{abstract}

Keywords electrocatalytic biomass conversion; surface and interface chemistry; two-dimensional materials; high valueadded organic chemicals; hydrogen

\section{1 引言}

为了摆脱对化石燃料的依赖和应对气候变暖等环 境危机, 清洁、可再生的能源如太阳能、风能、潮汐能、 地热能等有望成为驱动世界生产和社会运转的动力来 源 ${ }^{[1,2]}$. 然而, 该类能源的间歇性对其合理存储和快速转 换造成了巨大的挑战. 生物质是一种绿色的碳资源, 在 生产有机化学品方面具有来源丰富、年产量高、化学结 构多样、环境条件下普遍稳定等优点 ${ }^{[3-5]}$. 但在工业合成 有机化学品上仍然面临着高能耗、高污染和需要昂贵、 有毒催化剂的挑战 ${ }^{[6-9]}$. 通过电催化的方法, 可以在温和
条件下, 利用间歇式能源产生的电能驱动生物质电转化 为高附加值有机化学品 ${ }^{[10,11]}$. 此外, 利用生物质低氧化 电势的特性, 在阳极采用生物质氧化反应代替析氧反 应, 可以大幅度降低电解水制氢的能量消耗 ${ }^{[12-15]}$. 氢气 作为氢能源的载体, 具有零污染、可再生以及能量密度 高等优点, 被视为清洁、高能的理想燃料 ${ }^{[16,17]}$. 因而, 电 催化生物质转化不仅具有实现绿色生产高附加值有机 化学品的工业应用前景, 还具有存储可再生间歇式能 源、优化能源结构的潜力(图 1). 但是, 由于生物质具有 多个官能团及其转化反应涉及多个电子参与, 在电催化 生物质转化的过程中经常面临着反应动力学缓慢和产

*E-mail: ywliu@hust.edu.cn; zhaity@hust.edu.cn

Received June 24, 2020; published August 5, 2020.

Project supported by the National Natural Science Foundation of China (Nos. 21805102, 21825103, 51727809) and the Hubei Provincial Natural Science Foundation of China (No. 2019CFA002).

项目受国家自然科学基金(Nos. 21805102, 21825103, 51727809)和湖北省自然科学基金(No. 2019CFA002)资助. 
物复杂的问题. 同时, 生物质电催化反应还伴随着难以 避免的析氢反应或析氧反应的竞争, 这也限制了生物质 的电催化转化效率.

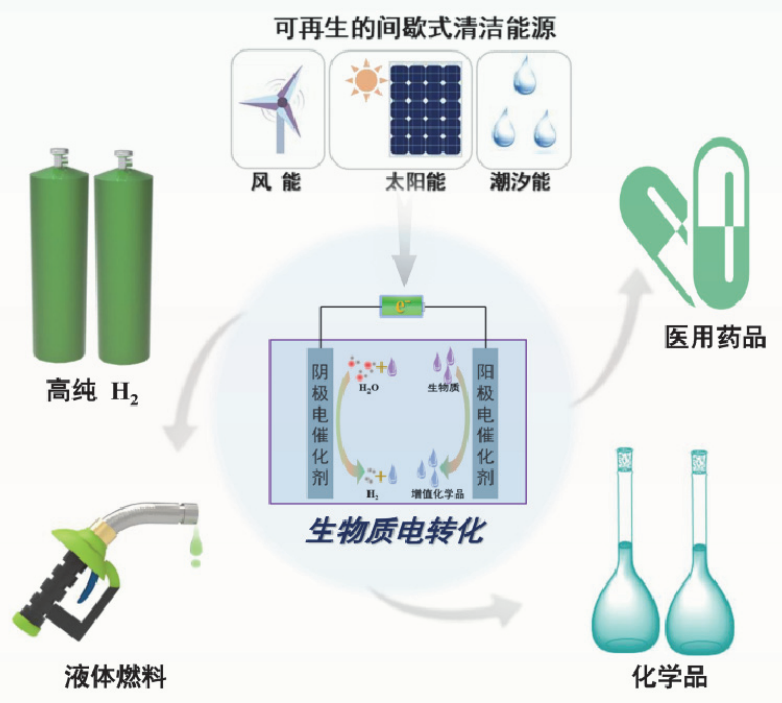

图 1 生物质电转化技术的前景

Figure 1 The prospect for biomass electro-transformation

电催化反应是一种发生在电催化剂表面的异相催 化 ${ }^{[18]}$. 由少量原子层组成的二维材料, 和块体材料相比 具有高比表面积、增强的导电性和大量暴露的活性位 点 ${ }^{[19,20]}$. 因此, 二维材料是作为电催化剂, 进行电催化 反应的良好平台. 电催化剂暴露的活性位点、表面反应 分子的富集吸附状态和表面与反应物之间的电荷转移 速率是影响电催化反应选择性、反应动力学的决定性因 素. 由于其超薄的特性, 通过表界面化学工程如调控本 征结构 ${ }^{[21]}$ 、构筑表面空位 ${ }^{[22]}$ 、引入表面杂原子 ${ }^{[23]}$ 和构建 表面协同界面 ${ }^{[24]}$ 能够显著改变二维材料表面的电子结 构和几何结构. 近年来, 表界面化学工程在调控二维材 料电催化生物质转化领域取得了一系列进展. 比如, 通 过改善其导电性 ${ }^{[25]}$, 增加高催化活性的活性位点暴

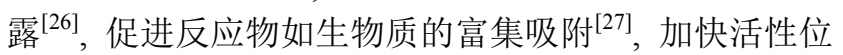
点与反应分子之间的电荷转移 ${ }^{[28]}$, 实现了对电催化生 物质转化选择性和电催化效率的调节.

本综述先总结了目前研究的电催化转化的生物质, 然后重点介绍了通过表界面化学工程对二维电催化材 料进行合理设计提升电催化生物质转化的选择性和效 率的最新研究进展, 讨论了表界面化学调控二维电催化 剂表面态增强催化性能的机理. 最后, 介绍了二维材料 电催化生物质转化向大规模有机合成应用在未来发展 中的技术挑战和前景.

\section{2 电催化转化的生物质}

生物质电转化是一种利用电解水装置, 以间歇式能 源驱动生物质在阳极氧化或阴极还原, 合成高附加值有
机化学品或制备高纯度氢气的新型技术 ${ }^{[29,30]}$. 按生物质 发生电催化反应后其转化的产物是否具有增值效应，我 们将其分为了两类: 消耗型生物质和增值型生物质.

\section{1 消耗型生物质}

消耗型生物质是指在阳极代替析氧反应发生低电 势氧化, 降低电解水制氢电势, 而无附加值产物伴随产 生的生物质. 目前, 已研究的消耗型生物质有尿素和水 合肼.

尿素电解 $\left(\mathrm{CO}\left(\mathrm{NH}_{2}\right)_{2}+\mathrm{H}_{2} \mathrm{O} \rightarrow 3 \mathrm{H}_{2}+\mathrm{N}_{2}+\mathrm{CO}_{2}\right)$ 可以 同时生产 $\mathrm{H}_{2}$ 和净化富尿素废水 ${ }^{[31]}$. 通过尿素氧化 (UOR)反应代替阳极的析氧反应，可以使水分解的热力 学电势从 $1.23 \mathrm{~V}$ 降低到 $0.37 \mathrm{~V}^{[32]}$. 然而, 尿素氧化反应

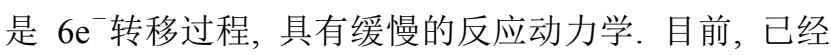
开发出了一系列具有尿素氧化反应性能的电催化剂, 例 如, $\mathrm{MnO}_{2}{ }^{[33]}$ 、金属相的 $\mathrm{Ni}(\mathrm{OH})_{2}{ }^{[28]}$ 和 $\mathrm{CoS}_{2}-\mathrm{MoS}_{2}{ }^{[34]}$ 等.

水合肼氧化 $\left(\mathrm{N}_{2} \mathrm{H}_{4}+4 \mathrm{HO}^{-} \rightarrow \mathrm{N}_{2}+4 \mathrm{H}_{2} \mathrm{O}+4 \mathrm{e}^{-}\right.$, $\mathrm{HzOR}$ )具有低于 $-0.33 \mathrm{~V}$ 的热力学电势, 此阳极氧化过 程只产生氮气和水, 不涉及任何温室气体的排放 ${ }^{[35]}$. 这 些优点使得水合肼氧化反应具有代替析氧反应促进水 分解制氢的潜在应用前景. 当前对于水合肼氧化反应的 电催化剂研究主要集中于 $3 \mathrm{~d}$ 过渡金属, 比如, $\mathrm{NiZn}^{[36]}$ 、 $\mathrm{CoS}_{2}{ }^{[37]} 、 \mathrm{FeP}^{[38]}$ 和 $\mathrm{Cu}_{3} \mathrm{P}^{[39]}$ 等.

\section{2 增值型生物质}

增值型生物质是指通过电催化转化能够合成具有 商业用途的高附加值产物的生物质. 按其是否伴随产生 氢气，增值型生物质可以分为两类. 一类是在阳极发生 氧化反应产生高附加值液态产物和耦合水分解在阴极 产生高纯度氢气的生物质. 这类生物质的研究主要有醇 醛类如甲醇 ${ }^{[40]}$ 、乙醇 ${ }^{[41-43]}$ 、丙三醇 ${ }^{[44,45]}$ 、苯甲醇 ${ }^{[46-48] 、}$ 呋喃甲醇 ${ }^{[12]}$ 、呋喃甲醛 ${ }^{[49]} 、 5$-差弪甲基糠醛 ${ }^{[50,51]}$ 和葡萄糖 等 ${ }^{[52-54]}$, 伯胺类如苯甲胺 ${ }^{[55,56]}$, 以及气相生物质乙烯 ${ }^{[57]}$ 等. 另一类是在阴极发生还原反应可以获得高附加值液 态产物的生物质，该还原过程通常伴随着析氢反应的发 生. 这类生物质主要是被还原生成 $\mathrm{C}=\mathrm{C}$ 双键的甲

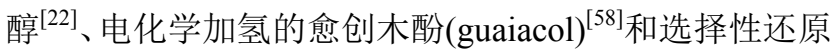
的芳硝基化合物 ${ }^{[59]}$.

醇醛类生物质在阳极发生氧化反应时，通过电催化 剂电化学活化其官能团羟基和醛基，可以选择性产生羧 酸、酮、醛和酯. 例如, Sun 等 ${ }^{[12]}$ 通过多孔 $\mathrm{Ni}$ 将苯甲醇 选择性电催化氧化为苯甲酸，其法拉第效率达到 $98 \%$, 同时产生了微量的苯甲醛; Chiang 等 ${ }^{[60]}$ 采用 $\mathrm{CuO}$ 作为电 催化剂, 获得了约 $60 \%$ 的高选择性将丙三醇电催化氧化 为二羟基丙酮; 郑南峰等 ${ }^{[61]}$ 使用超薄 $\mathrm{Co}_{3} \mathrm{O}_{4}$ 纳米片作为 阳极催化剂, 将乙醇选择性电氧化为了乙酸乙酯, 且法 拉第效率为 $98 \%$; 王双印等 ${ }^{[62]}$ 利用 $\mathrm{Ni}_{3} \mathrm{~N} @ \mathrm{C}$ 纳米片为阳 极电催化剂, 将 5-差甲基糠醛电催化氧化为了 2,5-呋喃 二甲酸, 达到了 $98 \%$ 的产率. 在阳极发生电催化氧化反 
应过程中, 合适的电催化剂不仅可以对醇类着基进行氧 化, 还可以同时促进醇类 $\mathrm{C}-\mathrm{C}$ 键的断裂, 生成高附加 值产物. 施剑林等 ${ }^{[63]}$ 通过负载于碳布上的 $\mathrm{Ni}-\mathrm{Mo}$ 氮化物 纳米片 (Ni-Mo-N/CFC) 将丙三醇电催化氧化为了甲酸, 且法拉第效率达到了 $95 \%$.

胺类生物质在阳极发生氧化反应时, 通过对伯胺电 化学脱氢, 可以将 $\mathrm{C}-\mathrm{N}$ 单键电转化为 $\mathrm{C} \equiv \mathrm{N}$ 三键, 实现 一步法将伯胺电转化为腈. 例如, 2018 年张兵等 ${ }^{[56]}$ 将 $\mathrm{NiSe}$ 纳米棒作为阳极催化剂, 首次实现了将伯胺电催 化氧化为腈. 以苯甲胺为例, 其转化为苯甲腈的法拉第 效率约为 99\%, 这证实了可以通过电化学氧化的方法将 伯胺转化为腈. 乙烯是世界产量最大的化工产品之一, 也是石油化工产业的核心. 电催化氧化乙烯生成高附加 值石油产品具有重要的工业意义和需求. Sargent 组 ${ }^{[57]}$ 在 2020 年首次提出了在室温和常压下利用电氧化乙烯一 步法直接合成乙二醇的策略. 他们利用 $\mathrm{Au}$ 掺杂 $\mathrm{Pd}$ 实现 了选择性生成乙二醇, 其法拉第效率约为 $80 \%$, 并且表 现出了 $100 \mathrm{~h}$ 的良好稳定性.

目前, 将 $\mathrm{C}_{1}$ 化合物转化为 $\mathrm{C}_{2}$ 化合物仍然是阻碍非 石油资源转化为高附加值化学品或然料领域发展的重 要原因. 其关键是对 $\mathrm{C}_{1}$ 化合物的选择性活化, 实现 $\mathrm{C}-$ $\mathrm{C}$ 键的耦合 ${ }^{[64]}$. 例如, 甲醇选择性可控地形成 $\mathrm{C}-\mathrm{C}$ 键. 詹东平等 ${ }^{[22]}$ 采用 $\mathrm{Co}_{3} \mathrm{ZnC} / \mathrm{NC}$ 作为阴极电催化剂, 在 $20{ }^{\circ} \mathrm{C}$ 和常压下实现了直接将甲醇电还原为乙醇, 其甲 醇转化速率、乙醇选择性和法拉第效率分别为 $257.0 \mathrm{~g}$ $\mathrm{cm}^{-2} \cdot \mathrm{h}^{-1} 、 95.1 \%$ 和 $12.5 \%$. 木质素广泛存在且未被充分 利用, 通过电化学还原法给愈创木酚加氢对于生物油的 合成和稳定化生产也具有重要意义. 王建国等 ${ }^{[58]}$ 以 $\mathrm{PtNiB} / \mathrm{CMK}-3$ 为电催化剂, 实现了在阴极利用电极表面 原位生成的吸附氢 $\left(\mathrm{H}_{\mathrm{ads}}\right)$ 电化学加氢愈创木酚, 生成 $\mathrm{KA}$ 油 (环已酮和环己醇混合物), 且法拉第效率达到了 86.2\%. 此外, 偶氮氧基、偶氮和氨基芳香族化合物在材 料合成领域具有广泛的需求 ${ }^{[65-67]}$. 电化学法选择性还原 芳硝基化合物是一种绿色且可控的合成偶氮氧基、偶氮 和氨基芳香族化合物的方法. 2020 年张兵等 ${ }^{[59]}$ 以 $\mathrm{CoP}$ 纳 米片为阴极电催化剂, 在不同的还原电位下将硝基芳香 化合物还原, 分别获得了偶氮氧基、偶氮和氨基芳香族 化合物.

\section{3 二维材料电催化生物质转化中的表界面化学}

二维材料表面电子结构和几何结构决定了其电催 化性能 ${ }^{[19,68]}$. 通过表界面化学工程调控, 可以实现活性 位点选择性暴露、改变活性位点局域配位环境、增强生 物质的富集吸附和加速电荷转移和电子传递. 在本节 中, 我们将调控二维电催化材料性能的表界面化学最新 研究成果分为四类(图 2): 表面本征结构, 表面空位, 表 面杂原子和表面协同界面.

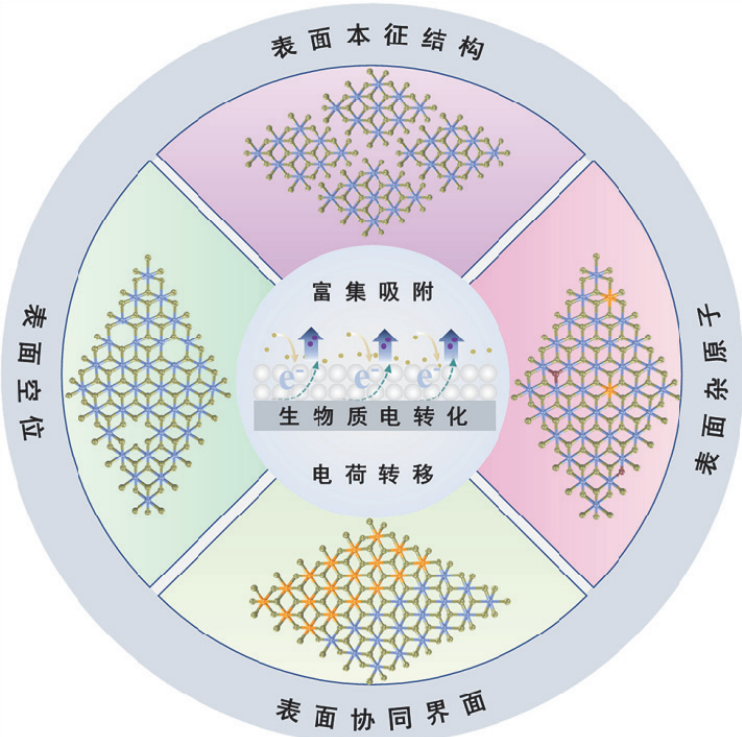

图 2 表面工程改性二维材料增强生物质电转化过程

Figure 2 Surface engineering modified two-dimensional materials enhance the process of biomass electro-transformation

\section{1 表面本征结构}

在异相催化体系中，反应物分子在异相催化剂表面 富集是实现其在活性位点化学吸附活化的先决条件, 催 化剂表面暴露的活性位点是确保吸附态的反应物分子 发生有效多电子反应的基石. 通过调控二维材料的本征 结构, 如暴露特定晶面、优化边缘位点与面内位点比例、 引入晶格扭曲等策略, 可以选择性暴露高活度的活性位 点、增大活性位点数量和改善反应物分子在催化剂表面 的化学吸附能力.

二维材料的不同晶面表面通常具有不同化学环境 的活性位点, 通过暴露具有最优活性位点的晶面可以实 现对二维材料的生物质电转化性能优化. 郑南峰课题 组 ${ }^{[61]}$ 在 $\mathrm{NH}_{3}$ 辅助和无模板的条件下直接一步水热法合 成了暴露(111) 晶面的超薄 $\mathrm{Co}_{3} \mathrm{O}_{4}$ 纳米片, 并将其用于乙 醇电氧化性能研究(图 $3 \mathrm{a} \sim 3 \mathrm{~g}$ ). $\mathrm{Co}_{3} \mathrm{O}_{4}$ (111) 晶面具有较 高的 $\mathrm{Co}^{3+} / \mathrm{Co}^{2+}$ 物质的量比 $\left(\mathrm{Co}^{3+}\right.$ 和 $\mathrm{Co}^{2+}$ 峰分别位于 $799.6 \mathrm{eV}$ 和 $781.5 \mathrm{eV}$ ), 从而超薄 $\mathrm{Co}_{3} \mathrm{O}_{4}$ 纳米片更易于获 得高活性 $\mathrm{Co}^{4+}$. 此外, 超薄 $\mathrm{Co}_{3} \mathrm{O}_{4}$ 纳米片还具有比立方 体形貌的 $\mathrm{Co}_{3} \mathrm{O}_{4}$ 更高的导电率和更快的离子传输能力, 从而促使超薄 $\mathrm{Co}_{3} \mathrm{O}_{4}$ 纳米片表现出了高活性和高选择性 的乙醇电化学氧化性能. 在 $1 \mathrm{~mol} \cdot \mathrm{L}^{-1}$ 乙醇和 $1 \mathrm{~mol} \cdot \mathrm{L}^{-1}$ $\mathrm{KOH}$ 溶液中, $\mathrm{Co}_{3} \mathrm{O}_{4}$ 纳米片的乙醇氧化电流密度达到 10 $\mathrm{mA} \cdot \mathrm{cm}^{-2}$ 时的电位为 $1.445 \mathrm{~V}$, 塔菲尔斜率为 138 $\mathrm{mV} / \mathrm{dec}$. 同时, 电氧化为乙酸乙酯的法拉第效率为 98\%.

二维材料的边缘位点因其不同于面内位点的特性 (如应力、配位数、化学态等), 而表现出更高的催化活 性, 如 $\mathrm{MoS}_{2}$ 的电催化析氢反应 ${ }^{[69]}$. 在生物质电化学氧 化过程中, $3 \mathrm{~d}$ 过渡金属基催化剂通常首先发生氧化反应 形成高价态金属位点，然后再进行生物质的氧化 ${ }^{[56,70]}$. 

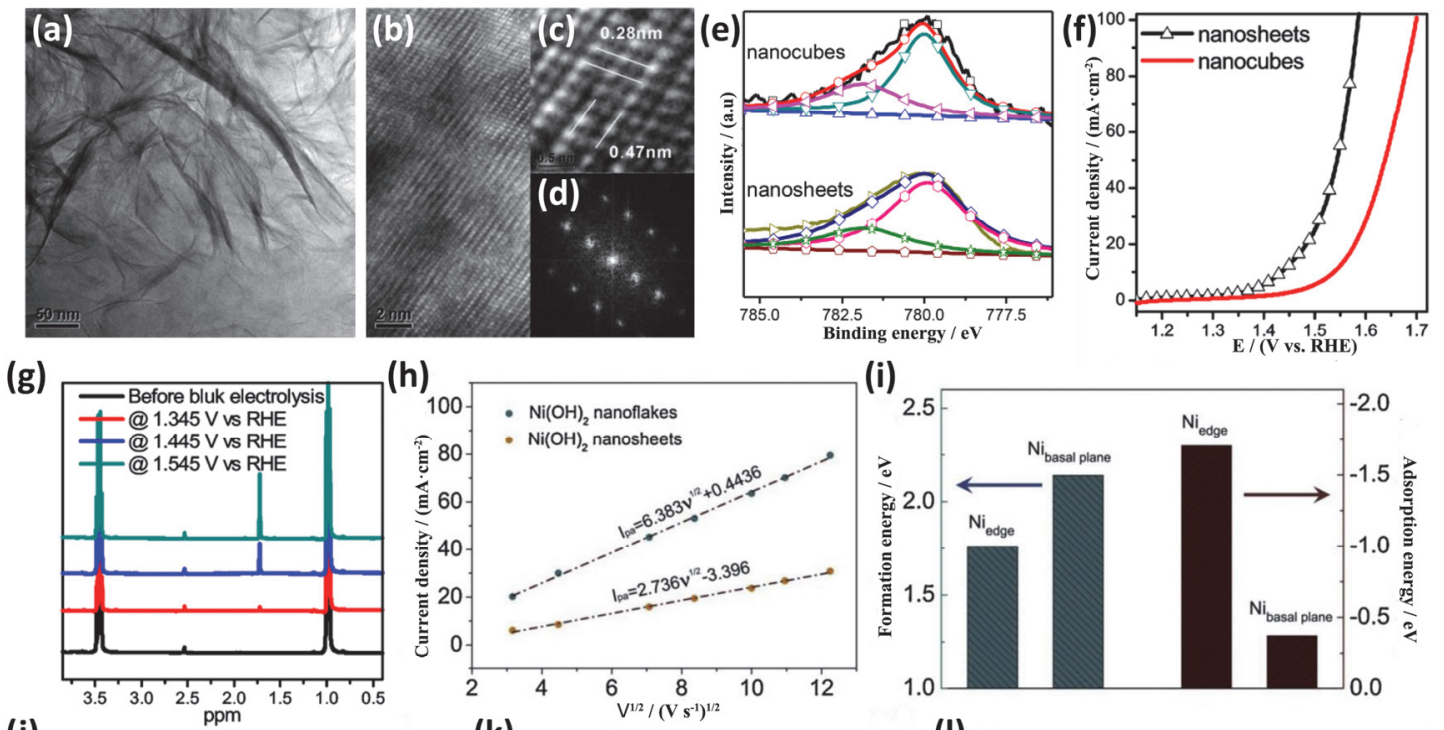

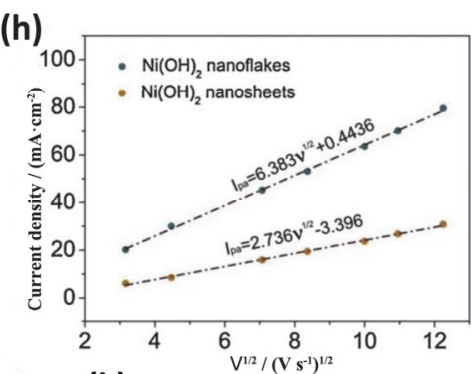

(k)

(i)

(j)

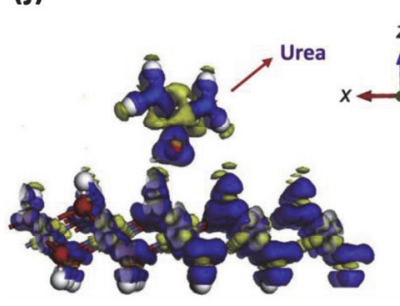

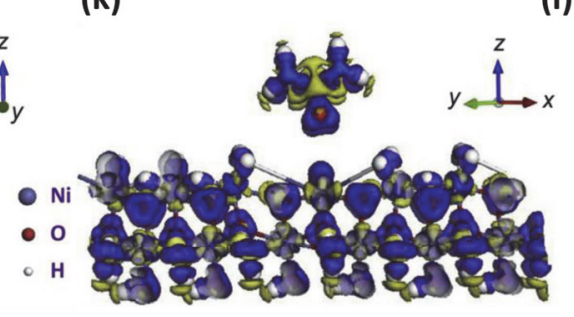

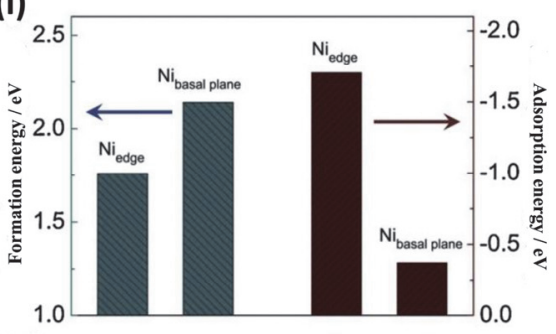

(I)

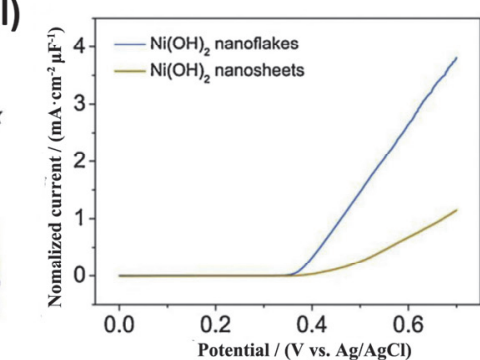

图 3 超薄 $\mathrm{Co}_{3} \mathrm{O}_{4}$ 纳米片的透射电子显微镜(TEM)图(a), 高分辨透射电子显微镜(HRTEM)图(b, c), 和(b)图中 $\mathrm{Co}_{3} \mathrm{O}_{4}$ 纳米片对应的快速傅里叶变换 (FFT)图(d). (e)纳米片和纳米立方体的 Co $2 p$ XPS 谱. 乙醇氧化的电催化性能: (f)纳米片和纳米立方体的极化曲线. (g)纳米片在不同电位下电解前 后产物的 ${ }^{1} \mathrm{H} \mathrm{NMR}$ 谱. (h) $1 \mathrm{~mol} \cdot \mathrm{L}^{-1} \mathrm{KOH}$ 溶液中 $\mathrm{Ni}(\mathrm{OH})_{2}$ 样品的阳极峰值电流密度与扫描速率平方根 $\left(I_{\mathrm{pa}}-v^{1 / 2}\right)$ 之间的线性关系. (i) 由 $\beta$ - $\mathrm{Ni}(\mathrm{OH})_{2}$ 计 算出的 $\beta-\mathrm{NiOOH}$ 的形成能和在 $\mathrm{Ni}(\mathrm{OH})_{2}$ 纳米片的边缘和平面上的尿素分子吸附能. 尿素分子在 $\mathrm{Ni}(\mathrm{OH})_{2}$ 纳米片的边缘 $(\mathrm{j})$ 和平面 $(\mathrm{k})$ 上的吸附以及 相应的差分电荷密度图. (1)通过 $C_{\mathrm{d} 1}$ 值归一化 $\mathrm{Ni}(\mathrm{OH})_{2}$ 样品的 LSV 曲线

Figure 3 (a) TEM and (b, c) HRTEM images of ultrathin $\mathrm{Co}_{3} \mathrm{O}_{4}$ nanosheets. (d) The corresponding FFT pattern of an individual $\mathrm{Co}_{3} \mathrm{O}_{4}$ nanosheet shown in panel b. (e) The high-resolution XPS spectra of Co $2 p$ the $\mathrm{Co}_{3} \mathrm{O}_{4}$ nanosheets and Nanocubes. Electrocatalytic performance of ethanol oxidation; (f) polarization curves of the nanosheets and nanocubes. (g) ${ }^{1} \mathrm{H}$ NMR spectra of products before and after bulk electrolysis at different potentials for $1 \mathrm{~h}$ on $\mathrm{Co}_{3} \mathrm{O}_{4}$ nanosheet. (h) Linear relationship between the anodic peak current density and the square root of the scan rate $\left(I_{\mathrm{pa}}-v^{1 / 2}\right)$ for $\mathrm{Ni}(\mathrm{OH})_{2}$ nanoflakes and $\mathrm{Ni}(\mathrm{OH})_{2}$ nanosheets in $1 \mathrm{~mol} \cdot \mathrm{L}^{-1} \mathrm{KOH}$ solution. (i) The calculated formation energies of $\beta$ - $\mathrm{NiOOH}$ from $\beta$ - $\mathrm{Ni}(\mathrm{OH})_{2}$ and adsorption energies of urea molecule on the edge and basal plane of $\mathrm{Ni}(\mathrm{OH})_{2}$ nanosheet. Illustration of the adsorption of urea molecule on the edge $(\mathrm{j})$ and basal plane $(\mathrm{k})$ of $\mathrm{Ni}(\mathrm{OH})_{2}$ nanosheet and the corresponding differential charge density. (l) LSV curves normalized by the $C_{\mathrm{dl}}$ values of $\mathrm{Ni}(\mathrm{OH})_{2}$ nanoflakes and $\mathrm{Ni}(\mathrm{OH})_{2}$ nanosheets

然而, 二维材料面内紧密排布的原子却阻碍了该电化学 相变过程. 因此, 通过减小二维材料的横向尺寸暴露出 更多的富活性边缘位点具有普遍增强生物质电催化活 性的潜力. 罗细亮课题组 ${ }^{[26]}$ 以尿素为电催化对象和二 维超薄 $\mathrm{Ni}(\mathrm{OH})_{2}$ 为催化剂模型, 研究了 $\mathrm{Ni}(\mathrm{OH})_{2}$ 纳米片 边缘位点在尿素电氧化反应中扮演的作用(图 3h〜31). 他们在室温条件下快速地合成了横向尺寸较小的、超薄 $\mathrm{Ni}(\mathrm{OH})_{2}$ 纳米片 $\left(\mathrm{Ni}(\mathrm{OH})_{2}\right.$ Nanoflakes $)$, 并把横向尺寸较 大的超薄 $\mathrm{Ni}(\mathrm{OH})_{2}$ 纳米片 $\left(\mathrm{Ni}(\mathrm{OH})_{2}\right.$ Nanosheets) 作为研究 边缘位点和其尿素电氧化性能之间关系的对比样. 这两 种催化剂的阳极峰电流密度 $\left(I_{\mathrm{pa}}\right)$ 与循环伏安 $(\mathrm{CV})$ 扫描速 率的平方根 $\left(v^{1 / 2}\right)$ 几乎呈线性关系(图 3h). $\mathrm{Ni}(\mathrm{OH})_{2}$ Nanoflakes 具有更大的斜率说明其表面的 $\mathrm{OH}^{-}$扩散能力 更强, 表明 $\mathrm{Ni}(\mathrm{OH})_{2}$ Nanoflakes 更易于生成活性的 $\mathrm{NiOOH}$. 然后通过密度泛函理论(DFT)计算研究了尿素 分子在催化剂表面的吸附状态(图 $3 \mathrm{i} \sim 3 \mathrm{k}$ ). $\mathrm{Ni}(\mathrm{OH})_{2}$ 边
缘的吸附能 $(-1.7056 \mathrm{eV})$ 明显小于面内的吸附能 $(-0.3719 \mathrm{eV})$. 同时, 不同于面内的 $\mathrm{Ni}$ 原子, 边缘的 $\mathrm{Ni}$ 原子与吸附的尿素分子之间具有更明显的电荷转移行 为. 这意味着边缘的活性位点具有比面内更高的尿素氧 化活性. 此外, $\mathrm{Ni}(\mathrm{OH})_{2}$ Nanoflakes 的电化学活性表面积 (ESCA) 归一化的电流密度明显大于 $\mathrm{Ni}(\mathrm{OH})_{2}$ Nanosheets(图 31), 证实了活性边缘位点对尿素氧化的 积极作用.

二维材料表面具有较高的表面能, 其表面化学键容 易发生一定程度的扭曲 ${ }^{[20]}$. 形成的晶格扭曲可同时实 现优化二维材料电催化活性位点数和改善其表面小分 子电催化的反应动力学, 使其展现出优异的生物质电催 化活性. 夏宝玉课题组 ${ }^{[71]}$ 合成了由紧密相连的纳米片 组成管状形貌的 $\mathrm{CoSe}_{2}$, 研究了其作为阳极催化剂对水 合肼的氧化性能(图 $4 \mathrm{a}, 4 \mathrm{~b}$ 和 $4 \mathrm{~d}$ ). 分析表明, $\mathrm{CoSe}_{2}$ 纳米 片卷曲边缘具有明显的晶格扭曲, 导致了丰富的缺陷和 
开放的边缘位点(图 4b). 由具有晶格扭曲的纳米片组成 管状结构的 $\mathrm{CoSe}_{2}$ 为水合肼电化学氧化提供了丰富的活 性位点、良好的界面接触和方便快捷的物质传输. 在不 同水合肼浓度的 $1 \mathrm{~mol} \cdot \mathrm{L}^{-1} \mathrm{KOH}$ 溶液中, $\mathrm{CoSe}_{2}$ 电催化 水合肼氧化的电流密度随着水合肼浓度的增加而显著 增大(图 4d). 此外, 在 $1 \mathrm{~mol} \cdot \mathrm{L}^{-1} \mathrm{KOH}$ 电解液中添加 0.5 $\mathrm{mol} \cdot \mathrm{L}^{-1}$ 水合肼后的全解水性能表明, 采用 $\mathrm{CoSe}_{2}$ 催化 的水合肼氧化反应代替阳极的析氧反应能显著降低电 解水技术的能量消耗.

严雅等 ${ }^{[72]}$ 也利用热分解金属有机钼前驱体在还原 石墨烯纳米片上分布均匀地针定了高密度缺陷的结晶 MoP 颗粒, 他们采用 HRTEM 表征, 发现 MoP 纳米颗粒 中的缺陷包括纳米孪晶、晶界、位错和堆垛层错(图 4c), 存在的高密度晶格缺陷能增强表面对反应分子的化学 吸附和暴露出更多的活性位点, 提升 MoP 的电催化活 性. 采用 $\mathrm{X}$ 射线光电子能谱(XPS)分析表面, 获得的富 高密度缺陷的 $\mathrm{MoP} / \mathrm{rGO}$ 表面具有高浓度的 $\mathrm{P}$. 电化学测 试表明, $\mathrm{MoP} / \mathrm{rGO}$ 具有良好的水合肼氧化性能, 达到 10 $\mathrm{mA} \cdot \mathrm{cm}^{-2}$ 时仅需 $84 \mathrm{mV}$ 的超小过电势(图 4e). 此外,
$\mathrm{MoP} / \mathrm{rGO}$ 还可以作为阴极析氢材料, 具有成为双功能 催化剂的潜力. 以 $\mathrm{MoP} / \mathrm{rGO}$ 同时作为阴极和阳极催化 剂组装的 $\mathrm{HER} \| \mathrm{HzOR}$ 电解池仅需 $0.74 \mathrm{~V}$ 外加电压便能 实现 $100 \mathrm{~mA} \cdot \mathrm{cm}^{-2}$ 的析氢电流密度(图 4f).

\section{2 表面空位}

电催化反应过程通常是发生在电催化剂的表面, 由 于二维材料具有较大的比表面积, 因此将空位引入二维 电催化剂表面是改善二维材料电催化性能的有效策 略 ${ }^{[73,74]}$. 引入表面空位不仅有利于增加配位不饱和的活 性位点, 还改变了空位位点邻域的电子结构, 从而改善 反应物分子在催化剂表面富集状态、促进反应物分子的 化学吸附和加速活性位点与吸附态反应物之间的电子 转移. 目前, 已经研究出多种控制电催化剂表面阳离子 空位和阴离子空位形成的有效策略, 例如在还原或惰性 气氛中高温处理、化学还原、等离子体刻蚀等 ${ }^{[75-77]}$. 引 入的阳离子和阴离子空位对二维电催化剂的电输运能 力和活性位点吸附反应物的能力产生重要影响.
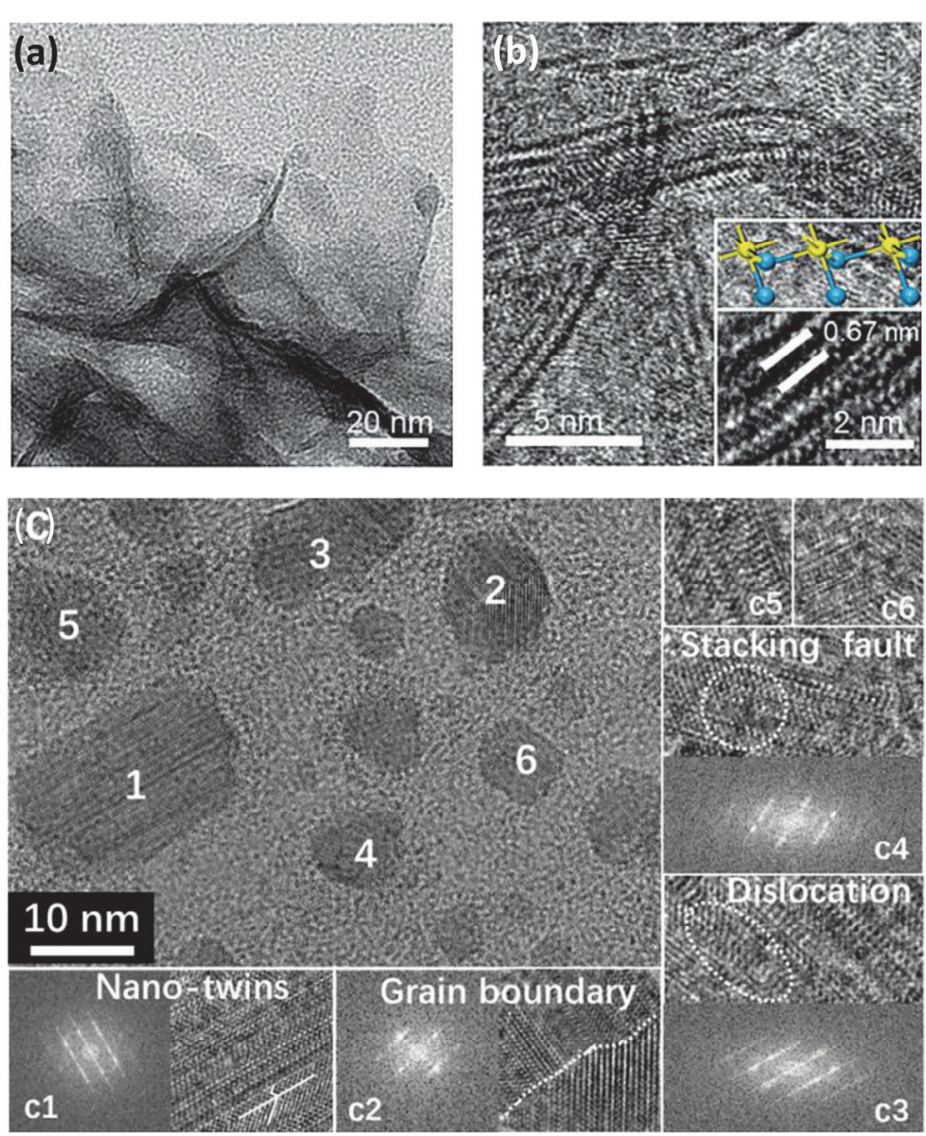

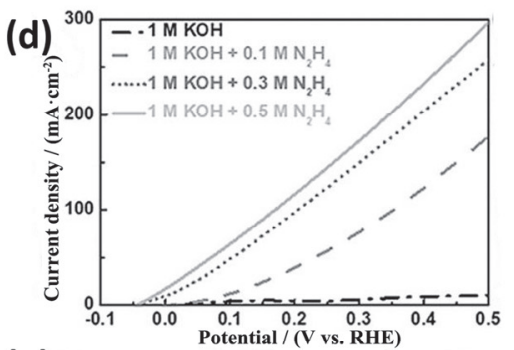

(e)

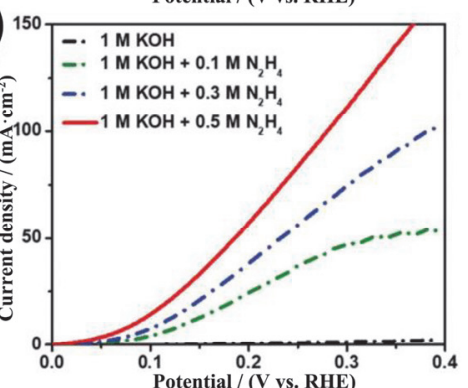

(f)

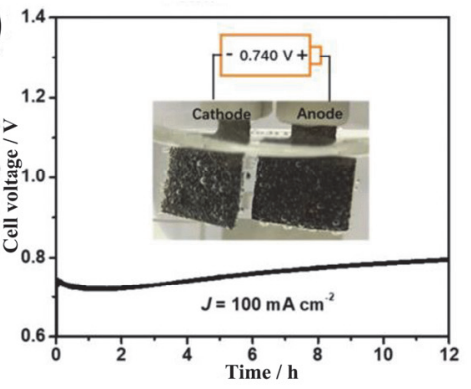

图 4 (a, b) $\mathrm{CoSe}_{2}$ 纳米片的 TEM 图像. 插图(b): $\mathrm{CoSe}_{2}$ 的分层和建模结构. (c) D-MoP/rGO 的 TEM 图像. (d)在含不同水合肼浓度的 $1 \mathrm{~mol} \cdot \mathrm{L}^{-1} \mathrm{KOH}$ 溶液中的 $\mathrm{CoSe}_{2}$ 的水合肼氧化 $\mathrm{LSV}$ 曲线. (e)在含不同水合肼浓度的 $1 \mathrm{~mol} \cdot \mathrm{L}^{-1} \mathrm{KOH}$ 溶液中的 $\mathrm{D}-\mathrm{MoP} / \mathrm{rGO}$ 的水合肼氧化 $\mathrm{LSV}$ 曲线. (f)在 $100 \mathrm{~mA}$. $\mathrm{cm}^{-2}$ 时 $\mathrm{D}-\mathrm{MoP} / \mathrm{rGO} \| \mathrm{D}-\mathrm{MoP} / \mathrm{rGO}$ 杂化池的稳定性测试.

Figure 4 (a, b) TEM images of tubular $\mathrm{CoSe}_{2}$ nanosheets. Inset of (b): the layered and modeled structures of $\mathrm{CoSe}_{2}$. (c) Inverse-FFT TEM images of defects in D-MoP/rGO. (d) Hydrazine oxidation LSV polarization curves of $\mathrm{CoSe}_{2}$ in $1 \mathrm{~mol} \cdot \mathrm{L}^{-1} \mathrm{KOH}$ containing different hydrazine concentrations. (e) LSV polarization curves of D-MoP/rGO in $1.0 \mathrm{~mol} \cdot \mathrm{L}^{-1} \mathrm{KOH}$ containing different amounts of hydrazine. (f) The hybrid cell stability test with a $\mathrm{D}-\mathrm{MoP} / \mathrm{rGO} \| \mathrm{D}-\mathrm{MoP} / \mathrm{rGO}$ couple at $100 \mathrm{~mA} \cdot \mathrm{cm}^{-2}$ 
金属空位的引入, 可以调控活性位点的化合价, 提 升活性位点活化效率, 增强二维材料的导电性. 宋礼 等 ${ }^{[78]}$ 通过可控的水解策略获得了可控镍空位 $\left(\mathrm{V}_{\mathrm{Ni}}\right)$ 浓度 的 $\mathrm{Ni}(\mathrm{OH})_{2}$ 纳米片 $\left(\mathrm{V}_{\mathrm{Ni}}\right.$-rich $\left.\alpha-\mathrm{Ni}(\mathrm{OH})_{2}\right)$, 研究了金属 $\mathrm{Ni}$ 空位对尿素电催化氧化性能的影响(图 5). 他们提出环 氧丙烷 $(\mathrm{PO})$ 介导的碱化沉淀策略制备 $\mathrm{V}_{\mathrm{Ni}}$-rich $\alpha-\mathrm{Ni}(\mathrm{OH})_{2}$, 该策略通过调节水解过程中水含量控制形 核速率和生长过程, 制备了一系列 $\mathrm{V}_{\mathrm{Ni}}$ 浓度的 $\mathrm{Ni}(\mathrm{OH})_{2}$ 纳米片 $\left(\mathrm{V}_{\mathrm{Ni}}-\mathrm{rich} \alpha-\mathrm{Ni}(\mathrm{OH})_{2}-x, x=1 \sim 4\right.$, 其中水含量越 少, 数字越大). 采用 $\mathrm{X}$ 射线吸收精细结构(XAFS)测试 显示 $\mathrm{V}_{\mathrm{Ni}^{-}}-\alpha-\mathrm{Ni}(\mathrm{OH})_{2}-x$ 的 $\mathrm{Ni}-\mathrm{Ni}$ 配位数 $(\mathrm{CN})$ 随着 $x$ 的变大 而减小, 而 $\mathrm{Ni}$ 的化合价逐渐升高, 证明了合成过程中水 含量的减少有利于 $\mathrm{V}_{\mathrm{Ni}}$ 的形成, 并且空位的存在促进了 $\mathrm{Ni}$ 化合价升高(图 5a). 随后, DFT 计算结果表明, $\mathrm{V}_{\mathrm{Ni}}$-rich $\alpha-\mathrm{Ni}(\mathrm{OH})_{2}$ 费米能级处的态密度(DOS) 随着 $\mathrm{V}_{\mathrm{Ni}}$ 浓度的增加而连续增强, 而且在高 $\mathrm{V}_{\mathrm{Ni}}$ 浓度还出现了新 的缺陷能级 (图 $5 \mathrm{~d} \sim 5 \mathrm{~h}$ ), 这意味着 $\mathrm{V}_{\mathrm{Ni}}$ 浓度的增加诱导 了电子电导率增加, 促进了电荷转移. 同时, 玻尔磁子 从 $2 \mu_{\mathrm{B}}$ 到 $1.75 \mu_{\mathrm{B}}$ 的连续减小表示 $\mathrm{e}_{\mathrm{g}}$ 轨道的电子自旋填 充减少, 这意味着金属-氧键强度的增强, 从而改善其 电催化活性. 此外, 随着 $\mathrm{V}_{\mathrm{Ni}}$ 浓度的增加, 由 $\alpha-\mathrm{Ni}(\mathrm{OH})_{2}$ 转化为 $\gamma-\mathrm{NiOOH}$ 的形成能垒逐渐降低(图 5c), 因而 $\mathrm{V}_{\mathrm{Ni}}$ 浓度的增加具有增强电催化活性的潜力. 在 $0.33 \mathrm{~mol}$ $\mathrm{L}^{-1}$ 尿素和 $1 \mathrm{~mol} \cdot \mathrm{L}^{-1} \mathrm{KOH}$ 溶液中的电化学测试结果表 明(图 5b): 随着 $\mathrm{V}_{\mathrm{Ni}}$ 浓度的增加, 尿素氧化的电流密度 不断增加和起始电位逐渐降低.

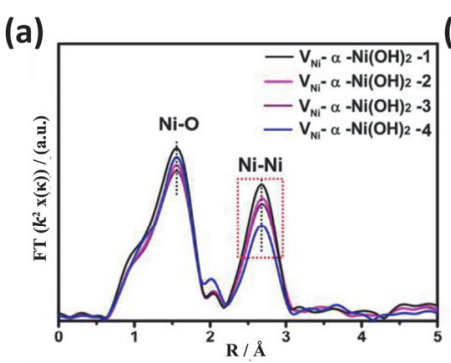

(d)
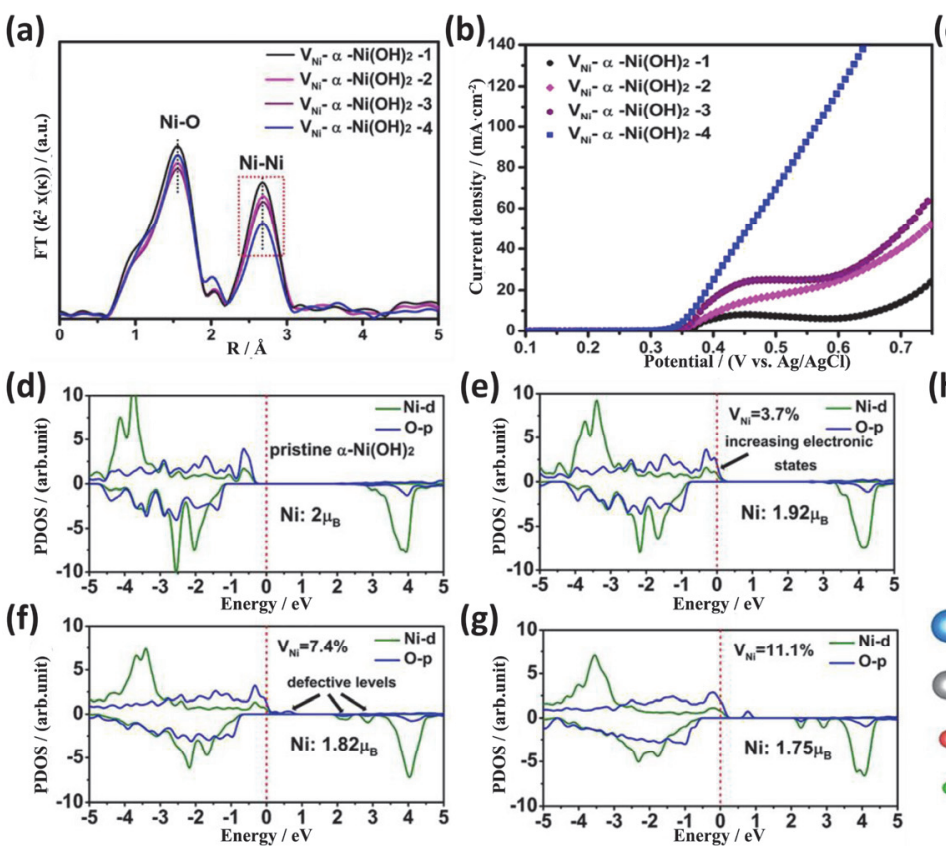

(e) 10

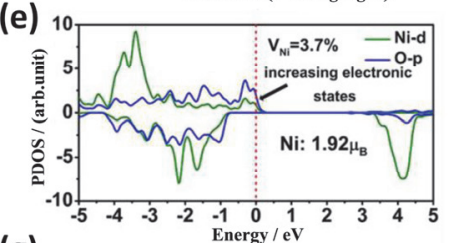

(g)

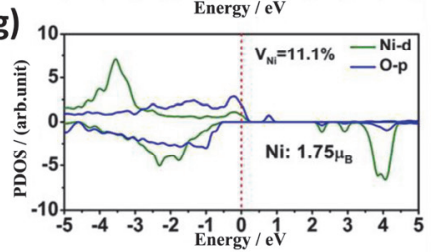

不同于金属空位，氧空位的引入，不仅可以优化二 维材料的活性位点数量、提高其导电率和调节生物质吸 附能, 还能通过参与生物质电转化过程改变其原始的反 应途径, 实现对电催化生物质转化性能的优化. 例如, 罗细亮课题组 ${ }^{[25]}$ 通过在空气气氛中快速高温处理 $\mathrm{Ni}$ 基 超薄纳米片制备了富含氧空位 $\left(\mathrm{V}_{\mathrm{O}}\right)$ 的超薄 $\mathrm{NiO}$ 纳米片 ( $\mathrm{V}_{\mathrm{O}}$-rich ultrathin $\mathrm{NiO}$ nanosheet), 研究了氧空位对甲醇 氧化性能的影响(图 $6 \mathrm{e} \sim 6 \mathrm{~h}$ ). 与贫 $\mathrm{V}_{\mathrm{O}}$ 超薄 $\mathrm{NiO}$ 纳米片 ( $\mathrm{V}_{\mathrm{O}}$-poor ultrathin $\mathrm{NiO}$ nanosheet)相比, $\mathrm{V}_{\mathrm{O}}$-rich ultrathin $\mathrm{NiO}$ nanosheet 表现出了更快的氧迁移能力、增强的氧存 储和吸附能力、以及更多的表面活性氧(图 6h). 在 0.5 $\mathrm{mol} \cdot \mathrm{L}^{-1}$ 甲醇和 $1 \mathrm{~mol} \cdot \mathrm{L}^{-1} \mathrm{KOH}$ 溶液中, $\mathrm{V}_{\mathrm{O}}$-rich ultrathin $\mathrm{NiO}$ nanosheet 作为阳极电催化剂时具有更优的电催化 甲醇氧化反应性能(图 $6 \mathrm{~g}$ ). 进一步分析表明, $\mathrm{V}_{\mathrm{O}}$-rich ultrathin $\mathrm{NiO}$ nanosheet 具有更快的 $\mathrm{OH}^{-}$扩散速率(图 $6 \mathrm{~h})$, 这意味着该催化剂表面更易于形成具有电活性的 $\mathrm{NiOOH}$ ，从而为甲醇氧化提供了更多的活性位点. 同 时, 表面富氧空位的 $\mathrm{NiO}\left(\mathrm{V}_{\mathrm{O}}-\mathrm{NiO}\right)$ 具有 $1.08 \mathrm{eV}$ 的较小 带隙, 而不含氧空位的 $\mathrm{NiO}$ 带隙为 $1.6 \mathrm{eV}$, 这表明氧空 位的存在增强了 $\mathrm{V}_{\mathrm{O}}$-rich ultrathin $\mathrm{NiO}$ nanosheet 的电子 输运能力. 此外, 他们也研究了甲醇分子在活性位点的 吸附能力(图 6e 和 6f). 结果表明: 含有氧空位的表面具 有更高的电子离域化程度, 这促使氧空位附近的 $\mathrm{Ni}^{2+}$ 处 于易于吸附含氧配体(如甲醇)的活化状态, 随后通过吸 附含氧配体形成了六配位的结构, 降低甲醇吸附能, 加 速甲醇电氧化反应的动力学过程.

图 5 (a) $\mathrm{V}_{\mathrm{Ni}^{-}} \alpha-\mathrm{Ni}(\mathrm{OH})_{2}-x$ 的傅立叶变换结果. (b)在含 $0.33 \mathrm{~mol} \cdot \mathrm{L}^{-1}$ 尿素的 $1.0 \mathrm{~mol} \cdot \mathrm{L}^{-1} \mathrm{KOH}$ 中 $\mathrm{UOR}$ 的 $\mathrm{LSV}$ 曲线. (c)由不同 $\mathrm{V}_{\mathrm{Ni}}$ 浓度的 $\alpha-\mathrm{Ni}(\mathrm{OH})_{2}$ 计算得到的 $\gamma-\mathrm{NiOOH}$ 的形成能. $(\mathrm{d} \sim \mathrm{g})$ DFT 计算的 $\mathrm{V}_{\mathrm{Ni}}$ 浓度分别为 $0,3.7 \%, 7.4 \%$ 和 $11.1 \%$ 的 $\alpha-\mathrm{Ni}(\mathrm{OH})_{2}$ 的 DOS 谱. 红色虚线是费米能级 设置为零. (h) $V_{\mathrm{Ni}}$ 掺入引起费米能级的部分电荷密度的模拟分布

Figure 5 (a) Fourier transformed results of $\mathrm{V}_{\mathrm{Ni}^{-}} \alpha-\mathrm{Ni}(\mathrm{OH})_{2}-x$ samples. (b) LSV curves for UOR in $1.0 \mathrm{~mol} \cdot \mathrm{L}^{-1} \mathrm{KOH}$ with the presence of $0.33 \mathrm{~mol} \cdot \mathrm{L}^{-1}$ urea. (c) The calculated formation energies for $\gamma-\mathrm{NiOOH}$ from $\alpha-\mathrm{Ni}(\mathrm{OH})_{2}$ with different $\mathrm{V}_{\mathrm{Ni}}$ concentrations. $(\mathrm{d} \sim \mathrm{g}) \mathrm{DFT}-$ based $\mathrm{DOS}$ spectra of $\alpha-\mathrm{Ni}(\mathrm{OH})_{2}$ with $\mathrm{V}_{\mathrm{Ni}}$ concentrations of $0,3.7 \%, 7.4 \%$, and $11.1 \%$, respectively. The red dashed line is the Fermi level set to zero. (h) The simulated distribution of partial charge density at the Fermi level induced by $\mathrm{V}_{\mathrm{Ni}}$ incorporation 


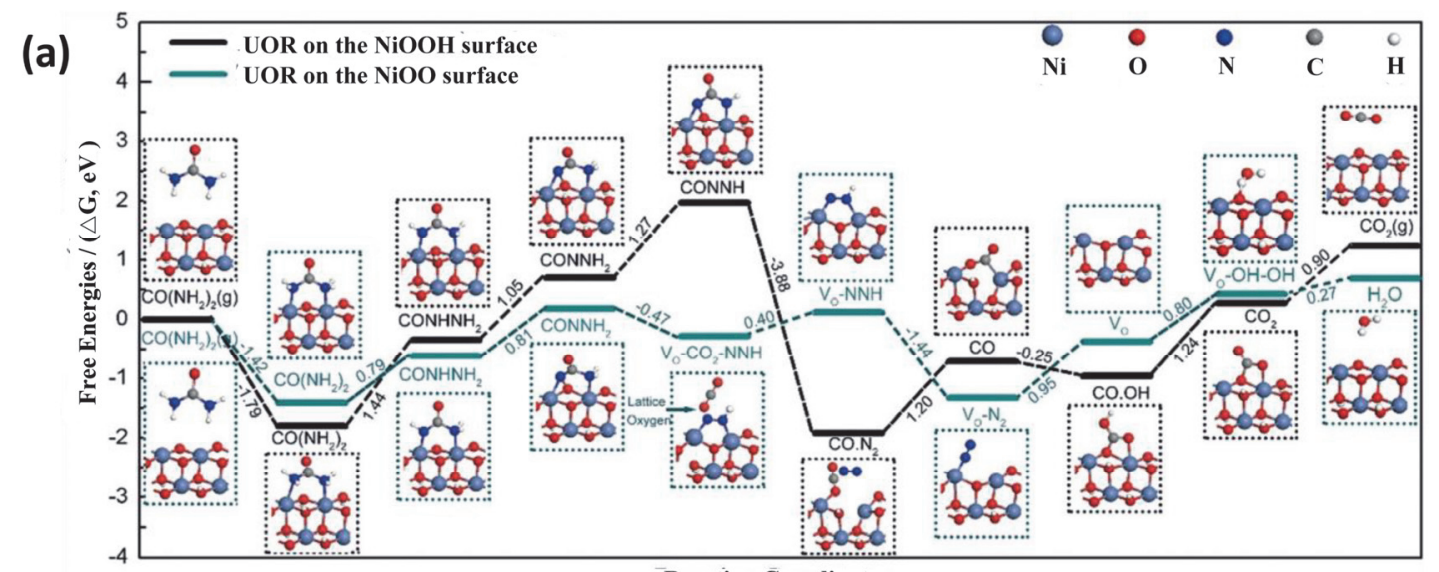

(b)

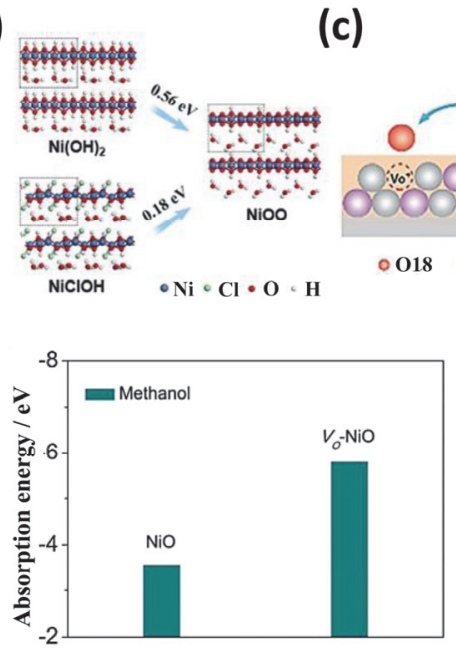

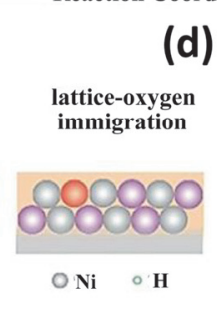

$(\mathrm{g})$

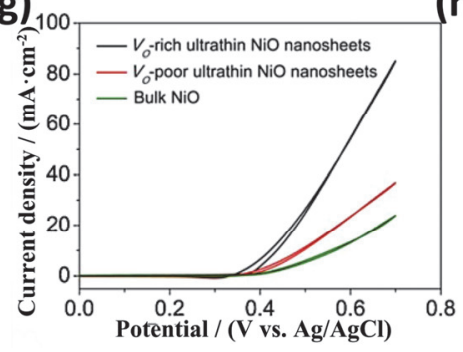

(h)

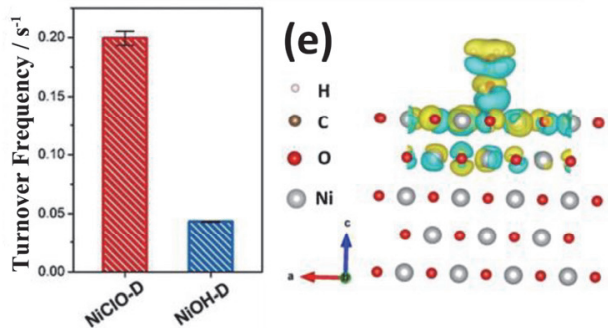

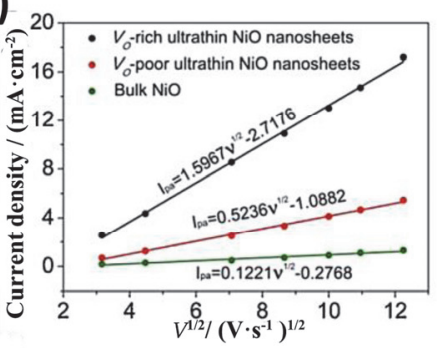

图 6 (a)在 $\mathrm{NiOO}$ 和 $\mathrm{NiOOH}$ 表面上沿 UOR 反应路径的吉布斯自由能. (b)从 $\mathrm{Ni}(\mathrm{OH})_{2}$ 和 $\mathrm{NiClOH}$ 到 $\mathrm{NiOO}$ 模型的形成能. (c) UOR 反应中晶格氧参 与的图示. (d)在 $1.6 \mathrm{~V}$ (vs. RHE)下 NiClO-D 和 NiOH-D 的转换频率. (e)甲醇分子在 $\mathrm{V}_{\mathrm{O}}-\mathrm{NiO}$ 样品表面上的吸附以及 $\mathrm{NiO}$ 随氧空位的变形电荷密度. (f) 甲醇分子在 $\mathrm{NiO}$ 和 $\mathrm{V}_{\mathrm{O}}-\mathrm{NiO}$ 样品上的吸附能. (g) 甲醇氧化的循环伏安法 $(\mathrm{CV})$ 曲线. (h) 在 $1 \mathrm{~mol} \cdot \mathrm{L}^{-1} \mathrm{KOH}$ 溶液中, 阳极峰值电流与扫描速率的平 方根 $\left(I_{\mathrm{pa}}-v^{1 / 2}\right)$ 之间的线性关系.

Figure 6 (a) The Gibbs free energy along the reaction pathways of UOR on the $\mathrm{NiOO}$ and $\mathrm{NiOOH}$ surfaces. (b) The formation energy from $\mathrm{Ni}(\mathrm{OH})_{2}$ and $\mathrm{NiClOH}$ to NiOO models. (c) Illustration of lattice-oxygen involvement during UOR. (d) Comparison of turnover frequency for the NiClO-D and NiOH-D at $1.6 \mathrm{~V}$ (vs. RHE). (e) Illustration of the adsorption of methanol molecules onto the surface of $\mathrm{V}_{\mathrm{O}}-\mathrm{NiO}$ sample and the deformation charge density of $\mathrm{NiO}$ with oxygen vacancy. (f) Adsorption energy of methanol molecules on the $\mathrm{NiO}$ and $\mathrm{V}_{\mathrm{O}} \mathrm{NiO}$ samples. (g) Cyclic voltammetry (CV) curves for methanol oxidation. (h) Linear relationship between the anodic peak current and the square root of the scan rate $\left(I_{\mathrm{pa}}-v^{1 / 2}\right)$ in $1 \mathrm{~mol} \cdot \mathrm{L}^{-1} \mathrm{KOH}$ solution.

通过在生物质电催化反应过程中原位产生可逆的 氧空位，可以促进具有更低反应能垒中间体的形成，改 变生物质电转化反应途径, 提升二维电催化材料的生物 质电转化活性. 彭慧胜等 ${ }^{[79]}$ 研究了在尿素氧化过程中 原位形成可逆的氧空位对尿素氧化反应性能的影响(图 $6 \mathrm{a} \sim 6 \mathrm{~d})$. 通过 DFT 计算表明: 在发生尿素氧化反应时, 在 $\mathrm{NiOO}$ 和 $\mathrm{NiOOH}$ 表面分别具有不同的尿素氧化反应 路径, 且 NiOO 表面发生的反应路径具有更小的尿素氧 化能垒(图 6a). 值得注意的是, 在尿素氧化反应过程中, $\mathrm{NiOOH}$ 表面的晶格氧原子不参与尿素氧化反应, 而 $\mathrm{NiOO}$ 表面晶格氧迁移给 $* \mathrm{CONNH}_{2}$ 形成氧空位和 $* \mathrm{~V}_{\mathrm{O}}-\mathrm{CO}_{2} \mathrm{NNH}$. 此外, 活性位点的再生过程也转变为能 垒仅需 $0.27 \mathrm{eV}$ 的* $\mathrm{V}_{\mathrm{O}}-\mathrm{OH}-\mathrm{OH}$ 的水脱附. 此时, 氧空位 被来自电解质的氧原子填充, 形成了具有完整晶格的 $\mathrm{NiOO}$. 因此, NiOO 表面晶格氧通过形成氧空位参与尿
素氧化不仅能降低电催化电势, 还能减小活性位点再生 能垒. 同时, $\mathrm{DFT}$ 计算还表明由 $\mathrm{O}$ 替换 $\mathrm{NiClOH}$ 中 $\mathrm{Cl}$ 和 $\mathrm{OH}$ 基团比由 $\mathrm{O}$ 替换 $\mathrm{Ni}(\mathrm{OH})_{2}$ 中的 $\mathrm{OH}$ 基团更易于形成 $\mathrm{NiOO}$ (图 6b). 随后, 他们分别对作为前驱物的 $\mathrm{Ni}(\mathrm{OH})_{2}$ 和 $\mathrm{NiClOH}$ 纳米片进行了电化学还原, 并将获得的样品 分别命名为 $\mathrm{NiOH}-\mathrm{D}$ 和 $\mathrm{NiClO}-\mathrm{D}$. 在 $0.33 \mathrm{~mol} \cdot \mathrm{L}^{-1}$ 尿素 和 $1 \mathrm{~mol} \cdot \mathrm{L}^{-1} \mathrm{KOH}$ 溶液中的电化学测试结果表明: NiClO-D 具有比 NiOH-D 更高的尿素氧化反应活性(图 6d). 由于在晶格氧参与的反应路径中, 来自电解质中的氧将 迁移到催化剂表面所形成的氧空位 $\left(\mathrm{Vo}^{+}\right)$中. 因此, 他们 采用 ${ }^{18} \mathrm{O}$ 同位素标记质谱表征了在 ${ }^{18} \mathrm{O}$ 标记的 0.33 $\mathrm{mol} \cdot \mathrm{L}^{-1}$ 尿素和 $1 \mathrm{~mol} \cdot \mathrm{L}^{-1} \mathrm{KOH}$ 溶液中测试后的 $\mathrm{NiOH}-\mathrm{D}$ 和 NiClO-D(图 6c). 结果表明, NiClO-D 具有更高的 ${ }^{18} \mathrm{O} /{ }^{16} \mathrm{O}$ 比例，证明了 $\mathrm{NiClO}-\mathrm{D}$ 以晶格氧参与的反应途 径驱动尿素氧化, 从而表现出更优的尿素电氧化性能. 
此外, 阳离子空位和阴离子空位共存于二维材料 时, 可以协同作用, 增加二维材料表面的正电荷位点分 布, 增强对生物质的化学吸附能力 ${ }^{[80]}$. 我们组通过原位 电化学转换 Ni-MOFs 超薄纳米片, 获得了同时富 $\mathrm{Ni}$ 空 位和富 $\mathrm{O}$ 空位的 $\mathrm{Ni}(\mathrm{OH})_{2}$ 纳米片 ${ }^{[81]}$. 首先借助同步辐射 $X$ 射线吸收精细结构光谱(XAFS)和 XPS 谱研究了富空 位 $\mathrm{Ni}(\mathrm{OH})_{2}$ 纳米片的电子结构(图 7a 和 $7 \mathrm{~b}$ ), 证实了富 $\mathrm{Ni}$ 空位和富 $\mathrm{O}$ 空位缺陷的成功引入. 经电化学测试表 明, 制备的富空位 $\mathrm{Ni}(\mathrm{OH})_{2}$ 纳米片具有明显增强的电氧 化正丙胺性能(图 7c). 随后, 为获得空位提升性能的机 制, 采用 DFT 计算研究了正丙胺的静电势分布. 结果表 明: 相对于正丙胺分子中的其他基团, 正丙胺中 $\mathrm{N}$ 原子 由于其不等性的 $\mathrm{sp}^{3}$ 杂化轨道中存在孤对电子, 其邻域 呈现负电势. 结合对正丙胺吸附在富空位 $\mathrm{Ni}(\mathrm{OH})_{2}$ 纳米 片表面的差分电荷密度图的分析(图 7d 和 7e), 我们认为 在该材料中, $\mathrm{Ni}$ 空位的存在能有效促进 $\mathrm{O}$ 空位的形成,
诱导正电荷位点在表面暴露, 从而增强正电荷位点化学 吸附含孤对电子的 $\mathrm{N}$ 原子能力, 进而加速攻击 $\mathrm{N}-\mathrm{H}$ 键 活化为正丙胺分子.

在二维材料表面，当阴离子和阳离子以原子簇形式 按化学计量比形成空位, 且原子簇尺寸达到一定比例时 会形成大量的纳米孔 ${ }^{[82]}$. 基于无机固体化学原理, 纳米 孔周围会产生大量的不饱和悬挂键. 通过在二维材料表 面构建纳米孔, 可以暴露出大量的活性位点和形成输运 反应物和产物的通道 ${ }^{[83]}$, 促进生物质的富集、化学吸附 和电化学活化. 我们组 ${ }^{[27]}$ 在双金属氢氧化物纳米片上 构建纳米孔, 实现了在乙醇电化学氧化过程中对乙醇分 子的空间分布和化学吸附协同调控，获得了显著提升的 乙醇电氧化性能(图 $4 \mathrm{~d} \sim 4 \mathrm{i}$ ). 我们通过将合成的具有双 柱层结构的金属有机骨架(MOFs)超薄纳米片作为前驱 体, 在温和条件下采用碱处理策略成功制备了表面分布 着直径为 $2 \mathrm{~nm}$ 纳米孔的钴镍双金属氢氧化物纳米片 (a)

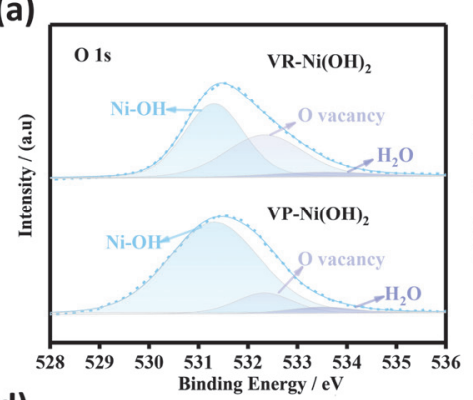

(d)

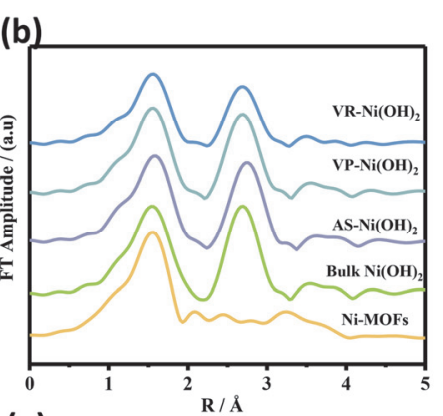

(e)

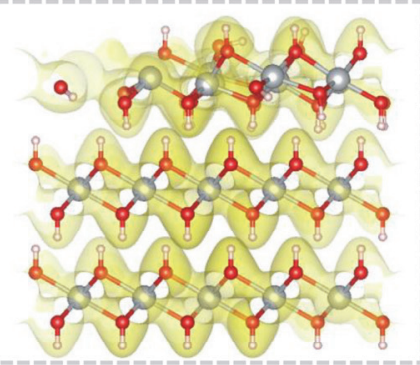

(g)

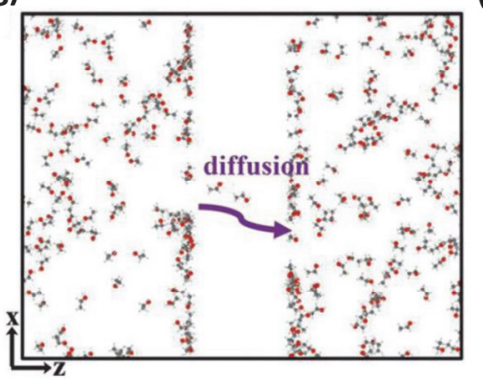

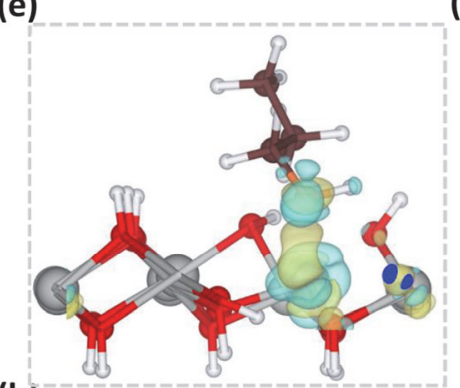

(h)

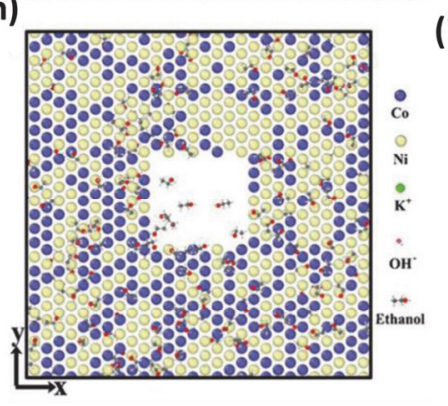

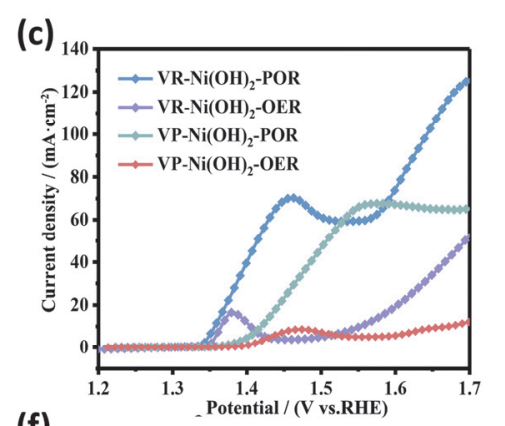

(f)

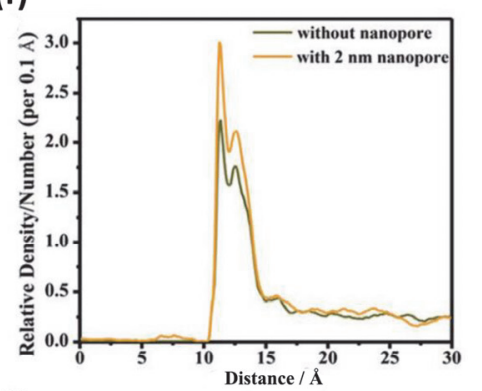

(i)

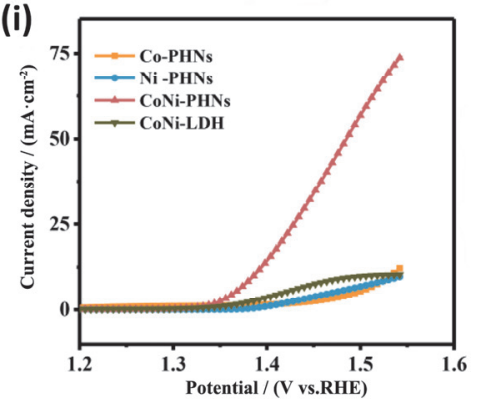

图 7 (a) VR-Ni(OH) $)_{2}$ 和 VP-Ni $(\mathrm{OH})_{2} \mathrm{O} 1 \mathrm{~s}$ 的 XPS 谱. (b) $\mathrm{Ni} \mathrm{K}$ 边对应的 FT 曲线. (c) 富缺陷 $\mathrm{Ni}(\mathrm{OH})_{2}$ 的 OER 和正丙胺氧化的极化曲线. (d) 富缺陷 $\mathrm{Ni}(\mathrm{OH})_{2}$ 的电荷密度. (e) 富缺陷 $\mathrm{Ni}(\mathrm{OH})_{2}$ 的差分电荷密度. 分子空间分布: (f)沿垂直于有/无纳米孔的 CoNi-PHNs 的方向, 乙醇分子的相对密度/数 量(每 $0.1 \AA$ )分布图. (g)乙醇分子通过 $2 \mathrm{~nm}$ 纳米孔. (h)纳米孔附近乙醇分子的富集. (i) 以 $5 \mathrm{mV} \cdot \mathrm{s}^{-1}$ 扫描速率进行乙醇氧化的各种催化剂的归一化极 化曲线.

Figure 7 (a) XPS O 1s spectra of VR-Ni(OH $)_{2}$ and VP-Ni(OH $)_{2}$. (b) The corresponding FT curves of Ni K-edge XANES spectra. (c) The normalized polarization curves for VR-Ni(OH $)_{2}$. (d) Charge density of the VR-Ni(OH $)_{2}$. (e) The charge density difference in the VR-Ni(OH $)_{2}$. Molecular spatial distribution. (f) Relative density/number (per $0.1 \AA$ ) profiles of ethanol molecules along the direction perpendicular to the CoNi-PHNs with/without nanopores. (g) Ethanol molecules pass through the $2 \mathrm{~nm}$ nanopore. (h) The enrichment of ethanol molecules near the nanopore. (i) The normalized polarization curves of various catalysts for ethanol oxidation at a scan rate of $5 \mathrm{mV} \cdot \mathrm{s}^{-1}$. 
(CoNi-PHNs). 电化学测试结果表明: 与同样分布着直 径 $2 \mathrm{~nm}$ 纳米孔的氢氧化钴 (Co-PHNs)、氢氧化镍 (Ni-PHNs) 和无孔的钴镍双金属氢氧化物(CoNi-LDH)相 比, CoNi-PHNs 具有较优的乙醇电氧化性能, 即较小的 乙醇氧化为乙酸电位 $(1.39 \mathrm{~V})$ 和较高的法拉第效率 $(99 \%)$. 随后, 我们采用分子动力学 $(M D)$ 模拟研究了电 解质溶质 (乙醇、 $\mathrm{K}^{+}$和 $\mathrm{OH}^{-}$) 在纳米孔周围的空间分布和 迁移行为. MD 模拟结果表明, 乙醇分子在邻近纳米孔 的区域具有明显的富集和吸附效应(图 4d), 相比而言, 纳米孔对 $\mathrm{K}^{+} 、 \mathrm{OH}$ 的影响可以忽略不计 (图 4e 和 4f). 并 且, 当纳米孔尺寸大于 $2 \mathrm{~nm}$ 时, 纳米孔在乙醇电化学氧 化反应过程中, 扮演着 “堤坝” 的作用(图 $4 \mathrm{~g}$ 和 $4 \mathrm{~h}$ ). 此 时, 乙醇分子可以通过渗透效应在纳米孔中穿梭, 并在 纳米孔周围产生积聚的趋势, 增加了乙醇分子的流动性 和改善了其与更多活性位点结合的能力, 从而表现出了 最优的乙醇电氧化性能.

\section{3 表面杂原子}

电催化剂的本征电输运能力和化学吸附反应物及 其反应中间体的能力, 是决定电催化效率的重要因素. 目前, 将杂原子引入电催化剂成为调控其电子态、导电 性和吸附能力的有效策略 ${ }^{[84]}$. 例如, 王海辉课题组 ${ }^{[41]}$ 利 用 $\mathrm{F}$ 修饰 $\mathrm{FeOOH}$ 调控了去质子化乙醇和 $\mathrm{OH}^{-}$与 $\mathrm{Fe}$ 位 点的结合能, 优化了 $\mathrm{Fe}$ 位点对反应物的吸附能力, 增加 了 $\mathrm{Fe}$ 位点的正电荷密度, 从而促进了析氧反应和乙醇 氧化反应的发生. 王功名课题组 ${ }^{[85]}$ 采用氮掺杂调控 $\mathrm{NiCo}_{2} \mathrm{~S}_{4}$ 表面电子态, 通过强的金属氮键削弱金属硫键, 调控活性位点的电子密度, 增强了 $\mathrm{NiCo}_{2} \mathrm{~S}_{4}$ 的导电性, 从而实现了在碱性条件下接近 $\mathrm{Pt} / \mathrm{C}$ 的析氢性能. 然而, 由于生物质氧化的多电子转移和其多个官能团参与吸 附的反应特性, 对二维材料活性位点的吸附能力和电输 运能力提出了更高的要求. 受益于二维材料超薄和高比 表面积特性, 在不破坏其本征主体结构的前提下二维材 料更容易实现杂原子掺杂，调控其生物质电转化性能.

在二维材料表面引入非金属杂原子, 通过调控其电 子态诱导二维材料相变, 被证明可有效调控活性位点对 反应物和中间体吸附能力, 提高导电性, 从而加快活性 位点与反应物及其中间体之间的电荷传输. 例如, 吴长 征等 ${ }^{[28]}$ 以 $\mathrm{H}_{2} \mathrm{~S}$ 作为硫源, 高温处理 $\mathrm{Ni}(\mathrm{OH})_{2}\left(\mathrm{P}-\mathrm{Ni}(\mathrm{OH})_{2}\right)$, 在未破坏 $\mathrm{Ni}(\mathrm{OH})_{2}$ 结构的情况下将硫掺入 $\mathrm{Ni}(\mathrm{OH})_{2}$, 制 备了金属性的 $\mathrm{Ni}(\mathrm{OH})_{2}$ 纳米片 $\left(\mathrm{M}-\mathrm{Ni}(\mathrm{OH})_{2}\right)($ 图 $8 \mathrm{a})$. 掺入 硫后, $\mathrm{M}-\mathrm{Ni}(\mathrm{OH})_{2}$ 的电子浓度明显增加, 从原始 $\mathrm{Ni}(\mathrm{OH})_{2}$ 的宽带隙转变为零带隙. 而且, $\mathrm{M}-\mathrm{Ni}(\mathrm{OH})_{2}$ 的电阻率随 温度升高而增加, 在室温下 $\mathrm{M}-\mathrm{Ni}(\mathrm{OH})_{2}$ 的电阻率为 3.13 $\times 10^{-4} \Omega$, 表现出了超高的导电性(图 $8 \mathrm{~b}$ ). 随后霍尔系 数 $\left(R_{\mathrm{H}}\right)$ 测试表明: $\mathrm{M}-\mathrm{Ni}(\mathrm{OH})_{2}$ 在不同温度的 $R_{\mathrm{H}}$ 均为负值 (图 $8 \mathrm{c}$ ), 证明了电子是 $\mathrm{M}-\mathrm{Ni}(\mathrm{OH})_{2}$ 的主要载流子. 同时, $\mathrm{M}-\mathrm{Ni}(\mathrm{OH})_{2}$ 纳米片的电子浓度约为 $10^{20} \mathrm{~cm}^{-3}$. 因此, 与 氧原子相比, 硫原子具有更大的原子半径和更小的电负
性, 硫的掺入削弱共价键和离域化电子, 从而改变 $\mathrm{Ni}(\mathrm{OH})_{2}$ 的电子结构, 使其表现出金属性. $\mathrm{M}-\mathrm{Ni}(\mathrm{OH})_{2}$ 纳 米片作为阳极催化剂, 在 $0.33 \mathrm{~mol} \cdot \mathrm{L}^{-1}$ 尿素和 $1 \mathrm{~mol} \cdot \mathrm{L}^{-1}$ $\mathrm{KOH}$ 溶液中具有优异的电催化尿素氧化反应性能(图 $8 \mathrm{~d})$. 与原始 $\mathrm{Ni}(\mathrm{OH})_{2}$ 相比, 其具有更高的催化活性和稳 定性. 在催化剂表面活性位点处 $\mathrm{CO}_{2}$ 脱附过程被认为是 尿素氧化反应的决速步骤, 而 $\mathrm{CO}_{2}$ 与催化剂表面较强的 吸附会导致催化剂中毒. 通过密度泛函理论(DFT)计算 发现 $\mathrm{M}-\mathrm{Ni}(\mathrm{OH})_{2}$ 具有较小的 $\mathrm{CO}_{2}$ 从表面活性物种脱附能 垒. 因此，表面硫的引入通过阻止 “中毒” 过程暴露出 更多的活性位点，与其良好的亲水性和高效的电子传输 协同作用, 增强了 $\mathrm{Ni}(\mathrm{OH})_{2}$ 电催化尿素氧化反应活性.

金属杂原子的引入，可以与原始金属活性位点发生 相互作用，改变其表面电子态，调节金属活性位点的生 物质电转化能力. 例如, 侯仰龙等 ${ }^{[86]}$ 通过牺牲模板法成 功地合成了多级空心纳米结构的 $\mathrm{Mn}$ 掺杂 $\mathrm{Ni}(\mathrm{OH})_{2}$ 纳米 片(图 $8 \mathrm{e} \sim 8 \mathrm{~h}$ ). $\mathrm{Mn}$ 掺杂 $\mathrm{Ni}(\mathrm{OH})_{2}$ 纳米片中的 $\mathrm{Ni}$ 具有较 低的电子密度和较高的氧化态(图 8e). 而且, Mn 掺杂 $\mathrm{Ni}(\mathrm{OH})_{2}$ 纳米片中存在的 $\mathrm{Mn}^{3+}$ 由于 Jahn-Teller 效应产生 系统畸变, 从而引起了 $\mathrm{Ni}(\mathrm{OH})_{2}$ 价带的改变. 此外, $\mathrm{Mn}$ 掺杂 $\mathrm{Ni}(\mathrm{OH})_{2}$ 纳米片的电子顺磁共振(EPR)表征结果显 示出一条单一的宽线(图 8f), 证明了 $\mathrm{Ni}$ 和 $\mathrm{Mn}$ 原子的自 旋引起了强偶极相互作用. 根据 $g$ 值确认了是局域晶体 场和电子相互作用产生的系统畸变. 产生的畸变提高了 电子迁移率, 增强了系统电导率. 将 $\mathrm{Mn}$ 掺杂的 $\mathrm{Ni}(\mathrm{OH})_{2}$ 纳米片作为阳极催化剂, 在 $0.5 \mathrm{~mol} \cdot \mathrm{L}^{-1}$ 甲醇和 $1 \mathrm{~mol}$ • $\mathrm{L}^{-1} \mathrm{KOH}$ 溶液中, 具有明显优于 $\mathrm{Ni}(\mathrm{OH})_{2}$ 纳米片的甲醇 电催化氧化性能 $(8 \mathrm{~g})$. 而且, $\mathrm{Mn}$ 掺杂后的 $\mathrm{Ni}(\mathrm{OH})_{2}$ 纳米 片循环 1000 次仍然保持着 $90 \%$ 的初始电流密度(图 $8 \mathrm{~h}$ ), 这表明通过 $\mathrm{Mn}$ 的掺杂能明显改善 $\mathrm{Ni}(\mathrm{OH})_{2}$ 电氧化甲醇 的稳定性. 这是通过引入非活性的金属杂原子改善二维 材料表面活性位点的生物质电转化性能. 孙旭平等 ${ }^{[87]}$ 也通过非活性的 $\mathrm{Zn}$ 掺杂 $\mathrm{CoP}$, 调节其电子结构, 使 Co 的 $\mathrm{d}$ 带发生下移, 增强了 $\mathrm{CoP}$ 电催化尿素分解的性能, 促进了阴极水分解析出氢气. 然而, 引入具有电催化活 性的金属杂原子，可以实现二维材料中多金属活性位点 之间的协同效应，促进电荷转移和反应物吸附，提升其 生物质电转化活性. 我们组 ${ }^{[27]}$ 合成了双金属 $\mathrm{CoNi}$ 穿孔 纳米片，通过同步辐射软 X 射线吸收谱(sXAS)、XPS 表 征和 DFT 计算证明了金属 $\mathrm{Co}$ 和 $\mathrm{Ni}$ 之间存在着明显的 电荷转移. 其中, $\mathrm{Ni}^{2+}$ 中的部分电子通过 $\mathrm{OH}^{-}$中的 $\mathrm{O}$ 转 移给了 $\mathrm{Co}^{2+}$. 失去部分电子的 $\mathrm{Ni}^{2+}$ 倾向于作为亲电体 吸附乙醇分子中的亲核基团，而得到部分电子的 $\mathrm{Co}^{2+}$ 倾向于吸附乙醇分子的亲电基团. 因此，双金属之间的 电荷转移行为促进了对乙醇分子的化学吸附.

\section{4 表面协同界面}

表面协同界面是指在二维材料表面通过两种材料 或结构的结合产生的相界面 ${ }^{[48,88]}$, 由于其界面两侧不同 
相具有不同的电子态 ${ }^{[24]}$ 或电化学活性 ${ }^{[63]}$, 在生物质电 催化转化过程中可以协同作用, 通过改善对生物质分子 的吸附能力 ${ }^{[24]}$ 、诱导高活性位点的暴露和促进电荷转移 及传输 ${ }^{[63]}$, 从而促使该材料表现出优异的电催化性能.

肖特基异质结中金属性相与半导体相之间费米能 级的差异驱动电子自发且定向地流过异质界面, 诱导形 成相对稳定的局域亲电/亲核界面. 因此, 通过构建肖特 基异质结调控二维材料表面电荷分布, 获得吸附型协同 界面, 可以实现对反应物吸附位点的精确调控, 从而提 升其生物质电转化活性. 我们组 ${ }^{[34]}$ 选择金属 $\mathrm{CoS}_{2}$ 和半 导体 $\mathrm{MoS}_{2}$ 为基本材料, 设计了具有丰富异质界面的 $\mathrm{CoS}_{2} / \mathrm{MoS}_{2}$ 肖特基异质结纳米片, 研究了肖特基异质结 效应对尿素氧化反应性能的影响(图 $9 \mathrm{a} \sim 9 \mathrm{~g}$ ). 我们首先 采用低温硫化经水热法生长的 Co-Mo 前驱体, 制备了 $\mathrm{CoS}_{2}-\mathrm{MoS}_{2}$ 肖特基催化剂. 然后, 通过 HRTEM 表征, 确 认了 $\mathrm{CoS}_{2}$ 和 $\mathrm{MoS}_{2}$ 之间存在着明显的异质界面(图 9b), 同时选区电子衍射(SEAD) 也进一步证明了 $\mathrm{CoS}_{2}$ 和 $\mathrm{MoS}_{2}$ 在纳米片上的共存(图 9c). 随后, 采用了同步辐射 -紫外光电子能谱表征了 $\mathrm{CoS}_{2}$ 和 $\mathrm{MoS}_{2}$ 的功函数. 结果 显示, $\mathrm{CoS}_{2}$ 和 $\mathrm{MoS}_{2}$ 的功函数分别为 $3.9 \mathrm{eV}$ 和 $4.8 \mathrm{eV}$ (图 9e), 这表明 $\mathrm{CoS}_{2}$ 和 $\mathrm{MoS}_{2}$ 形成肖特基异质结后，电子会 自发地从 $\mathrm{CoS}_{2}$ 转移至 $\mathrm{MoS}_{2}$ (图 9f). 同时, DFT 计算得到 的差分电荷密度图也显示异质结界面处电荷发生重新 排布, 电子从 $\mathrm{CoS}_{2}$ 转移至 $\mathrm{MoS}_{2}$. 此外, 我们还通过 XPS 进行验证, 结果显示 $\mathrm{CoS}_{2}-\mathrm{MoS}_{2}$ 的 Co $2 \mathrm{p}_{1 / 2}$ 和 Co $2 \mathrm{p}_{3 / 2}$ 峰相对于 $\mathrm{CoS}_{2}$ 向高结合能处偏移(图 $9 \mathrm{~g}$ ), 证明了电 子由 $\mathrm{CoS}_{2}$ 注入 $\mathrm{MoS}_{2}$. 因此, 这种自驱动的异质界面间 电荷转移所诱导的局部亲电和亲核区域将智能地吸附 尿素分子中的供电子/吸电子基团, 降低动力学能垒, 从 而促进尿素分解. 在 $0.5 \mathrm{~mol} \cdot \mathrm{L}^{-1}$ 尿素和 $1 \mathrm{~mol} \cdot \mathrm{L}^{-1} \mathrm{KOH}$ 溶液中的电化学测试结果表明, $\mathrm{CoS}_{2}-\mathrm{MoS}_{2}$ 异质结表现 出了优异的尿素催化活性(图 9d), 只需 $1.29 \mathrm{~V}$ 的电势达 到 $10 \mathrm{~mA} \cdot \mathrm{cm}^{-2}$ 的电流密度和具有 $60 \mathrm{~h}$ 的良好电催化尿 素氧化反应稳定性. 麦立强等 ${ }^{[24]}$ 也在碳纤维布上构建 了一种具有丰富 $\mathrm{Cu}_{4} \mathrm{~N} / \mathrm{Ni}_{3} \mathrm{~N}$ 界面的新型 $\mathrm{Cu}_{1} \mathrm{Ni}_{2}-\mathrm{N}$ 纳米 片, $\mathrm{Cu}_{4} \mathrm{~N}$ 和 $\mathrm{Ni}_{3} \mathrm{~N}$ 之间存在强电子相互作用, 诱导耦合 界面处电子重新分布, 展现出了强的水合肼氧化性能.

对于由金属和半导体性相的化合物组成的肖特基 异质结，可以在异质界面处提供更多的电荷定向转移和 氧化还原对活性位点. 例如, 晏成林等 ${ }^{[89]}$ 通过原位电化

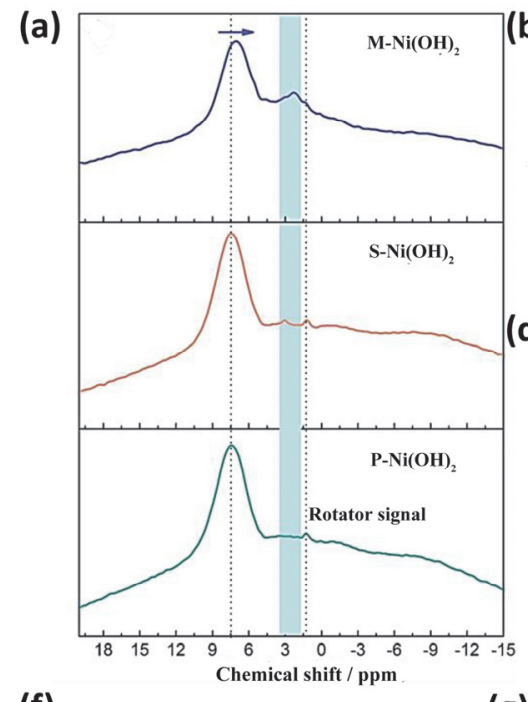

(f)

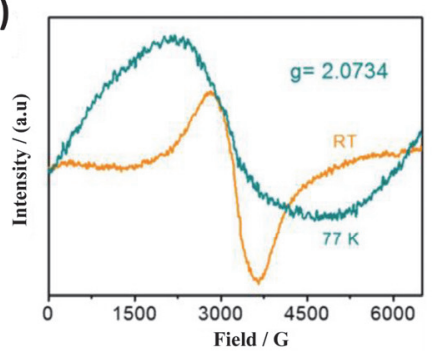

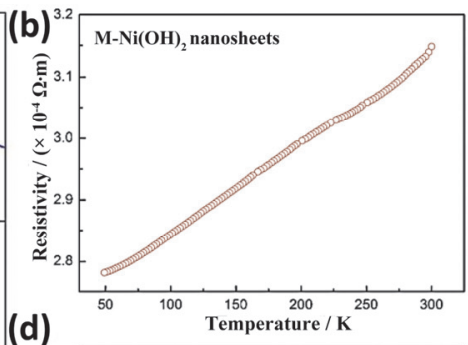
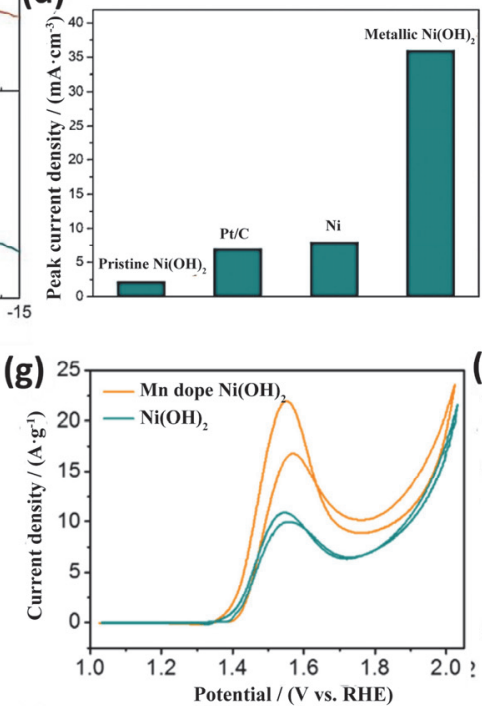

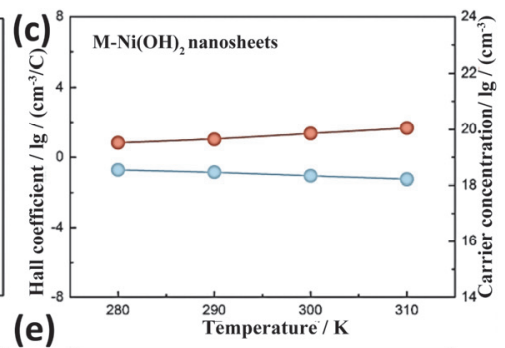

(e)

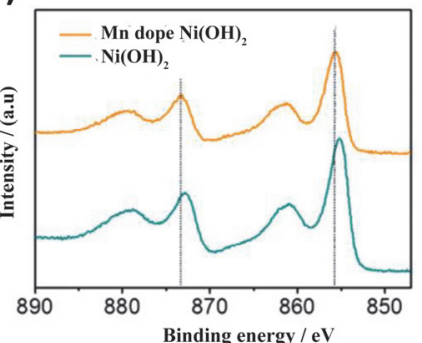

(h) 20

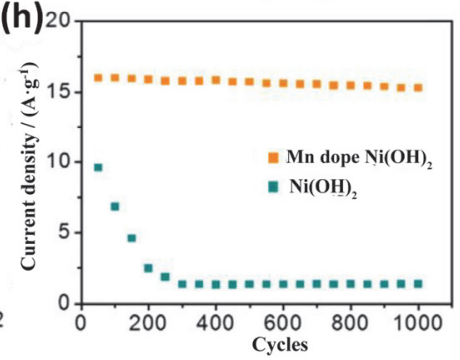

图 8 (a) 三个 $\mathrm{Ni}(\mathrm{OH})_{2}$ 样品的 ${ }^{1} \mathrm{H}$ 固态 MAS NMR 光谱. (b) M-Ni(OH $)_{2}$ 纳米片的温度依赖的电阻率曲线. (c) M-Ni(OH $)_{2}$ 纳米片的载流子浓度和霍尔 系数. (d) 不同电催化剂之间的峰值电流密度比较. (e)空心 $\mathrm{Mn}$ 掺杂的 $\mathrm{Ni}(\mathrm{OH})_{2}$ 纳米结构和 $\mathrm{Ni}(\mathrm{OH})_{2}$ 纳米片的 $\mathrm{Ni} 2 \mathrm{p}$ 的 XPS 谱. (f) 室温和 $77 \mathrm{~K}$ 下空 心 $\mathrm{Mn}$ 掺杂的 $\mathrm{Ni}(\mathrm{OH})_{2}$ 纳米结构的 $\mathrm{EPR}$ 谱. $(\mathrm{g})$ 在含 $0.5 \mathrm{~mol} \cdot \mathrm{L}^{-1}$ 甲醇的 $1 \mathrm{~mol} \cdot \mathrm{L}^{-1} \mathrm{KOH}$ 溶液中, 空心 $\mathrm{Mn}$ 掺杂的 $\mathrm{Ni}(\mathrm{OH})_{2}$ 纳米结构和 $\mathrm{Ni}(\mathrm{OH})_{2}$ 纳米 片的 CVs. (h) 空心锰掺杂的 $\mathrm{Ni}(\mathrm{OH})_{2}$ 纳米结构和 $\mathrm{Ni}(\mathrm{OH})_{2}$ 纳米片的电流密度与循环时间的关系.

Figure 8 (a) ${ }^{1} \mathrm{H}$ solid-state MAS NMR spectra of the three $\mathrm{Ni}(\mathrm{OH})_{2}$ samples. (b) Temperature-dependent resistivity of M-Ni( $\left.\mathrm{OH}\right)_{2}$ nanosheets. (c) Carrier concentration and Hall coefficient of $\mathrm{M}-\mathrm{Ni}(\mathrm{OH})_{2}$ nanosheets. (d) Peak current density comparison among different electrocatalysts. (e) XPS spectra of Ni $2 \mathrm{p}$ of hollow Mn doped $\mathrm{Ni}(\mathrm{OH})_{2}$ nanostructures and $\mathrm{Ni}(\mathrm{OH})_{2}$ nanosheets. (f) EPR spectra of hollow Mn doped $\mathrm{Ni}(\mathrm{OH})_{2}$ nanostructures at room temperature and $77 \mathrm{~K} .(\mathrm{g}) \mathrm{CVs}$ at hollow $\mathrm{Mn}$ doped $\mathrm{Ni}(\mathrm{OH})_{2}$ nanostructures and $\mathrm{Ni}(\mathrm{OH})_{2}$ nanosheets in the presence of $0.5 \mathrm{~mol} \cdot \mathrm{L}^{-1} \mathrm{methanol}$ in $1 \mathrm{~mol} \cdot \mathrm{L}^{-1} \mathrm{KOH}$ solution. (h) Current density vs cycling time of hollow $\mathrm{Mn}$ doped $\mathrm{Ni}(\mathrm{OH})_{2}$ nanostructures and $\mathrm{Ni}(\mathrm{OH})_{2}$ nanosheets. 
学法处理 $\mathrm{CoMn}_{2} \mathrm{O}_{4}$, 制备了 $\mathrm{CoMn} / \mathrm{CoMn}_{2} \mathrm{O}_{4}$ 肖特基复合 材料(图 9h $\sim 9 n$ ). 获得的 $\mathrm{CoMn} / \mathrm{CoMn}_{2} \mathrm{O}_{4}$ 具有丰富的金 属/金属氧化物界面(图 9i), 在其界面处的电子发生重新 排布并产生能带弯曲, 促使电子自发地从 $\mathrm{CoMn}$ 转移至 $\mathrm{CoMn}_{2} \mathrm{O}_{4}$. 这种电子在异质界面上的重新排布不仅可以 在金属和半导体相之间建立电子传输通道, 增加电化学 活性位点密度, 加速传质过程, 还可以有效减少反应中 间体的形成能垒, 从而加快总体反应速率. 在 $0.5 \mathrm{~mol}$ $\mathrm{L}^{-1}$ 尿素和 $1 \mathrm{~mol} \cdot \mathrm{L}^{-1} \mathrm{KOH}$ 溶液中的电化学测试结果表 明, $\mathrm{CoMn} / \mathrm{CoMn}{ }_{2} \mathrm{O}_{4}$ 比 $\mathrm{CoMn}_{2} \mathrm{O}_{4}$ 更容易驱动尿素电氧化 反应(图 9k). 同时, $\mathrm{CoMn} / \mathrm{CoMn}_{2} \mathrm{O}_{4}$ 还表现出了良好的 电催化尿素氧化反应稳定性, 经长时间的电催化反应 后, $\mathrm{CoMn} / \mathrm{CoMn}_{2} \mathrm{O}_{4}$ 仍然保持着良好的片状结构和金属/
金属氧化物异质结结构(图 9j). 采用 XPS 研究了其电子 结构，结果表明，在 $\mathrm{CoMn}_{2} \mathrm{O}_{4}$ 和 $\mathrm{CoMn} / \mathrm{CoMn}_{2} \mathrm{O}_{4}$ 的表面 均含有大量的氧化还原对 $\left(\mathrm{Co}^{2+} / \mathrm{Co}^{3+}\right.$ 和 $\left.\mathrm{Mn}^{2+} / \mathrm{Mn}^{3+}\right)$, 为 尿素分子的可逆吸附和产物的释放提供了丰富的电化 学活性位点(图 91 和 $9 \mathrm{~m}$ ). 此外, $\mathrm{Co}^{2+/ 3+} 2 \mathrm{p}$ 的结合能增 加, 而 $\mathrm{Mn}^{2+/ 3+} 2 \mathrm{p}$ 的结合能减小, 证明了复合材料中 $\mathrm{CoMn}_{2} \mathrm{O}_{4}$ 相中电子从 $\mathrm{Co}$ 转移至 $\mathrm{Mn}$. 当在肖特基催化剂 的界面上发生尿素氧化时, 由于静电相互作用, 吸电子 的羰基在 $\mathrm{CoMn}_{2} \mathrm{O}_{4}$ 侧被强烈吸附, 而富电子的氨基容 易吸附在 CoMn 侧. 这种 $\mathrm{CoMn}$ 和 $\mathrm{CoMn}_{2} \mathrm{O}_{4}$ 之间的协同 吸附作用将促进尿素分子中 $\mathrm{C}-\mathrm{N}$ 键的断裂, 加速尿素 分解产生 $\mathrm{CO}_{2}$ 和 $\mathrm{N}_{2}$ 的动力学过程. DFT 计算结果显示, $\mathrm{CoMn} / \mathrm{CoMn}_{2} \mathrm{O}_{4}$ 具有更小的 $\mathrm{CO}\left(\mathrm{NH}_{2}\right)_{2}$ 吸附能和 $\mathrm{H}_{2} \mathrm{O}$ 吸
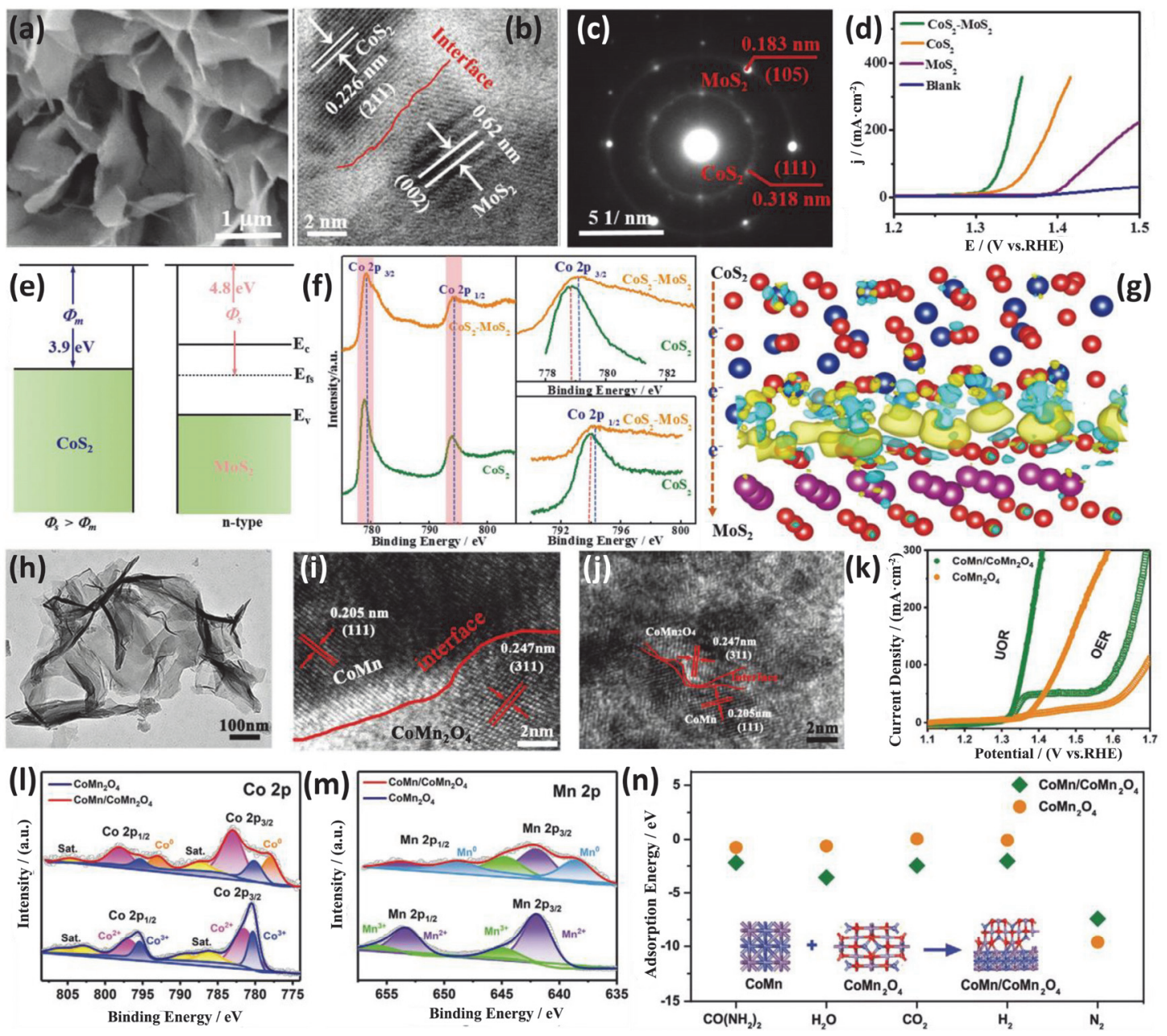

图 9 (a) $\mathrm{CoS}_{2}-\mathrm{MoS}_{2}$ 的 SEM 图. (b) $\mathrm{CoS}_{2}$ 和 $\mathrm{MoS}_{2}$ 之间形成的异质结放大图. (c) $\mathrm{CoS}_{2}-\mathrm{MoS}_{2}$ 的选区电子衍射图谱. (d) 在 $0.5 \mathrm{~mol} \cdot \mathrm{L}^{-1}$ 尿素和 $1 \mathrm{~mol} \cdot$ $\mathrm{L}^{-1} \mathrm{KOH}$ 溶液中的 UOR 性能测试. (e) 金属性的 $\mathrm{CoS}_{2}$ 和 $\mathrm{MoS}_{2}$ 形成肖特基接触前的能带图. (f) $\mathrm{CoS}_{2}-\mathrm{MoS}_{2}$ 和 $\mathrm{CoS}_{2}$ 的 XPS 图谱比较. (g) 异质结中 $\mathrm{CoS}_{2}$ 和 $\mathrm{MoS}_{2}$ 的差分电荷密度图, 黄色和蓝色的等值面分别代表了空间电荷的聚集和分离, 等值面的值是 $0.002 \mathrm{au} .(\mathrm{h}, \mathrm{i}) \mathrm{CoMn} / \mathrm{CoMn} \mathrm{O}_{4}$ 的 TEM 图和 HRTEM 图. (j) CoMn/CoMn $\mathrm{O}_{4}$ 进行 UOR 测试后的 HRTEM 图. (k) 各种催化剂的 UOR 和 OER 极化曲线. $\mathrm{CoMn}_{2} \mathrm{O}_{4}$ 和 $\mathrm{CoMn} / \mathrm{CoMn}_{2} \mathrm{O}_{4}$ 的 Co $2 \mathrm{p}$ XPS 谱(1)和 Mn 2p XPS 谱(m). (n) CO( $\left.\mathrm{NH}_{2}\right)_{2} 、 \mathrm{H}_{2} \mathrm{O} 、 \mathrm{CO}_{2} 、 \mathrm{H}_{2}$ 和 $\mathrm{N}_{2}$ 在 $\mathrm{CoMn}_{2} \mathrm{O}_{4}$ 和 $\mathrm{CoMn} / \mathrm{CoMn}_{2} \mathrm{O}_{4}$ 表面上的吸附能

Figure 9 (a) High-magnification SEM image of $\mathrm{CoS}_{2}-\mathrm{MoS}_{2}$. (b) Enlarged view of heterointerfaces between $\mathrm{CoS}_{2}$ and $\mathrm{MoS}_{2}$ lattice fringes. (c) The SEAD pattern recorded from a single nanosheet. (d) The test of the UOR activities in $1.0 \mathrm{~mol} \cdot \mathrm{L}^{-1} \mathrm{KOH}+0.5 \mathrm{~mol} \cdot \mathrm{L}^{-1}$ urea medium. (e) Energy band diagram of metallic $\mathrm{CoS}_{2}$ and n-type $\mathrm{MoS}_{2}$ before Schottky contact. (f) XPS spectra comparison of $\mathrm{CoS}_{2}-\mathrm{MoS}_{2}$ and $\mathrm{CoS}_{2}$. (g) The charge density difference in the heterostructure of $\mathrm{CoS}_{2}$ and $\mathrm{MoS}_{2}$. The yellow and blue isosurfaces represent charge accumulation and depletion in the space, respectively. And the isosurfaces level is 0.002 au. (h, i) TEM, and HRTEM of CoMn/CoMn $\mathrm{O}_{4}$. (j) HRTEM of CoMn $/ \mathrm{CoMn}_{2} \mathrm{O}_{4}$ after UOR test. (k) Polarization curves for the UOR and OER of various catalysts. High-resolution spectra of (l) Co $2 p,(m) \mathrm{Mn} 2 \mathrm{p}$ for $\mathrm{CoMn}_{2} \mathrm{O}_{4}$ and $\mathrm{CoMn} / \mathrm{CoMn}_{2} \mathrm{O}_{4}$, respectively. (n) Calculated adsorption energies of $\mathrm{CO}\left(\mathrm{NH}_{2}\right)_{2}, \mathrm{H}_{2} \mathrm{O}, \mathrm{CO}_{2}, \mathrm{H}_{2}$, and $\mathrm{N}_{2}$ on $\mathrm{CoMn}_{2} \mathrm{O}_{4}$ and $\mathrm{CoMn} / \mathrm{CoMn}_{2} \mathrm{O}_{4}$ surface 
附能，更大的 $\mathrm{N}_{2}$ 吸附能(图 9n). 这也证实了肖特基势垒 区能有效提高尿素的吸附率和稳定性.

将贵金属纳米颗粒材料针定于二维材料表面可以 构建出大量的吸附型协同表界面 ${ }^{[90]}$. 比如利用易于产 生 $\mathrm{OH}$ 活性物种的金属氢氧化物纳米片针定具有高生物 质氧化活性的贵金属纳米颗粒, 能够构建出具有强电子 相互作用的吸附型协同表界面, 促进电催化生物质转化 能力和增强其稳定性 ${ }^{[91]}$. 近年来, 李彦光组 ${ }^{[92]}$ 利用氢氧 化镍纳米片针定贵金属纳米颗粒在改善醇类生物质转 化效率和增强电催化稳定性方面取得了明显进展. 他们 在还原氧化石墨烯 $(\mathrm{rGO})$ 表面负载了针定着 $\mathrm{Pt}$ 纳米颗粒 的 $\mathrm{Ni}(\mathrm{OH})_{2}$ 纳米片 $(10 \mathrm{a} \sim 10 \mathrm{c})$, 相比于 $\mathrm{Pt} / \mathrm{Ni}(\mathrm{OH})_{2}$ 和 $\mathrm{rGO}$ 或 $\mathrm{Pt} / \mathrm{rGO}$ 和氢氧化镍物理复合, 表现出了明显增强的
甲醇电氧化活性和改善的稳定性(图 $10 \mathrm{~g}$ 和 $10 \mathrm{~h}$ ). 他们采 用 $\mathrm{X}$ 射线吸收谱证实了还原氧化石墨烯、 $\mathrm{Ni}(\mathrm{OH})_{2}$ 纳米 片与 $\mathrm{Pt}$ 纳米颗粒之间存在明显的强电子相互作用, $\mathrm{rGO}$ 和 $\mathrm{Ni}(\mathrm{OH})_{2}$ 或 $\mathrm{Pt}$ 之间分别通过 $\mathrm{C}-\mathrm{O}-\mathrm{Ni}$ 或 $\mathrm{C}-\mathrm{O}-\mathrm{Pt}$ 键共价偶联(图 $10 \mathrm{~d} \sim 10 \mathrm{f}$ ). 在甲醇电转化过程中, 活性 位点 $\mathrm{Pt}$ 纳米颗粒与相邻的 $\mathrm{Ni}(\mathrm{OH})_{2}$ 之间具有协同作用, $\mathrm{Pt}$ 位点产生的有毒碳化物被 $\mathrm{Ni}(\mathrm{OH})_{2}$ 有效移除, 从而有 效增强了甲醇电氧化性能. 而 $\mathrm{rGO}$ 不仅能够提供高的电 导率还能有效抑制 $\mathrm{Pt}$ 和 $\mathrm{Ni}(\mathrm{OH})_{2}$ 的聚集，从而改善甲醇 氧化稳定性.

活性型协同界面是由同时含电催化活性物种的两 相组成异质结形成的相界面, 其中一相同时具有电催化 活性物种和电化学活性物种. 在生物质电转化过程中,
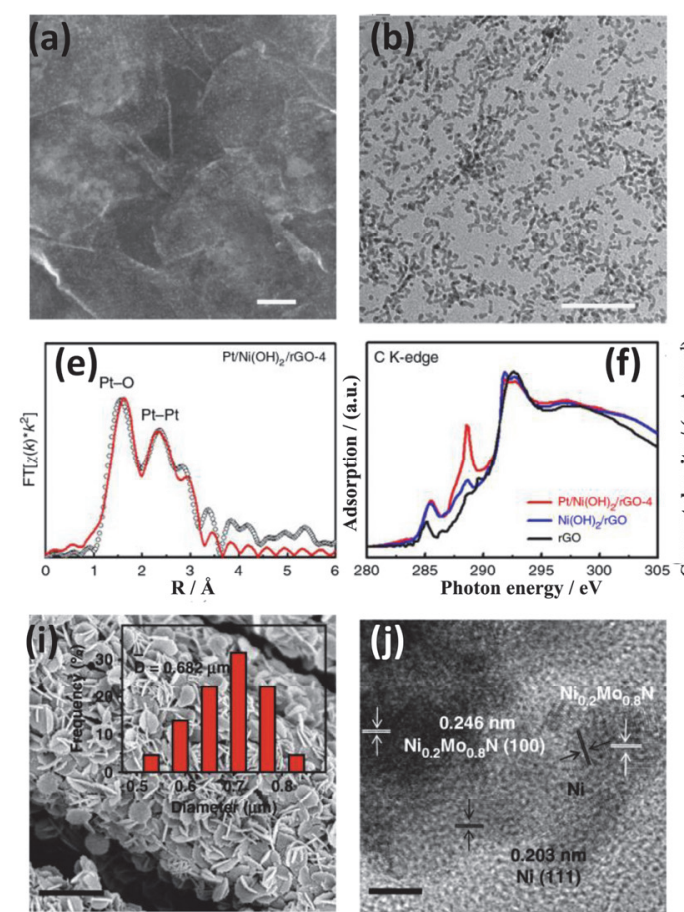

$(\mathrm{m})$

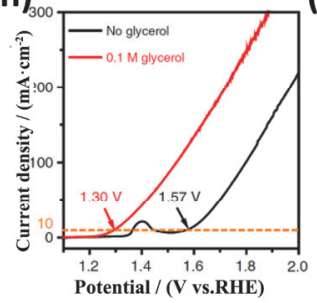

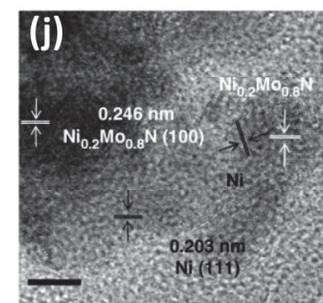

(n)

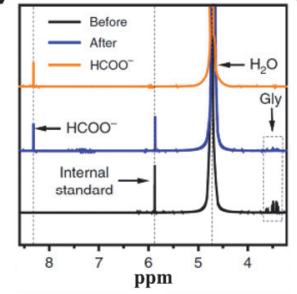

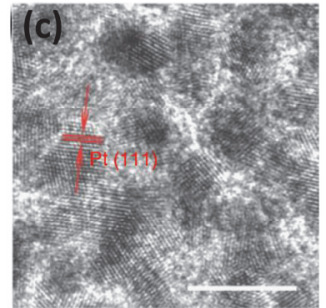
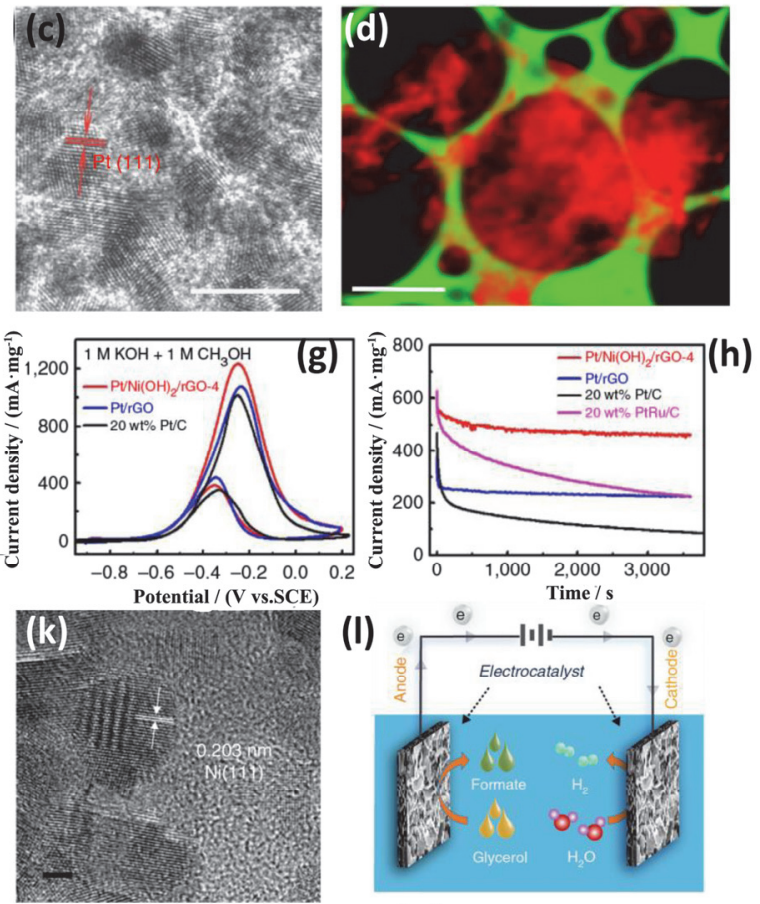

(o)
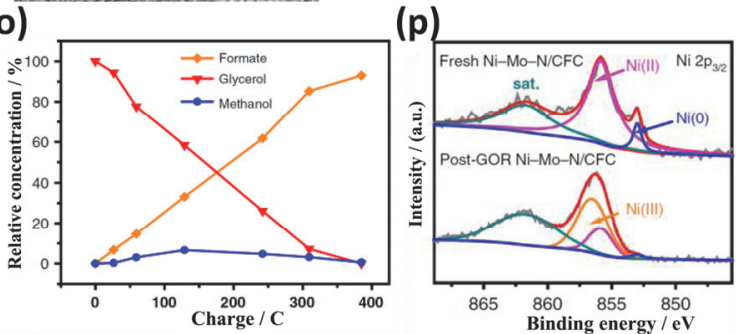

图 $10 \mathrm{Pt} / \mathrm{Ni}(\mathrm{OH})_{2} / \mathrm{rGO}-4$ 的 SEM 图(a)和 HRTEM 图(b, c). (d) Ni L 3 , 边在 $\mathrm{rGO}$ 纳米片载体上的扫描透射 X 射线显微镜 mapping 图. 标尺分别为: (a) $100 \mathrm{~nm}$, (b) $20 \mathrm{~nm}$, (c, d) $2 \mathrm{~nm}$. (e) Pt $\mathrm{L}_{3}$ 边对应的 EXAFS 谱傅里叶变换曲线. (f) $\mathrm{C} \mathrm{K}$ 边 XANES 光谱. (g) 在含 $1 \mathrm{~mol} \cdot \mathrm{L}^{-1}$ 甲醇的 $1 \mathrm{~mol} \cdot \mathrm{L}^{-1} \mathrm{KOH}$ 溶 液中的 CV 图. (h)稳定性测试. Ni-Mo-N/CFC 的 SEM 图(i)和 HRTEM 图(j). (k) Ni-Mo-N/CFC 进行 GOR 测试后的 HRTEM 图. (1)在丙三醇溶液中同 时制氢和甲酸盐的电解示意图. (m)在添加和不添加 $0.1 \mathrm{~mol} \cdot \mathrm{L}^{-1}$ 丙三醇的 $1 \mathrm{~mol} \cdot \mathrm{L}^{-1} \mathrm{KOH}$ 溶液中, Ni-Mo-N/CFC 的阳极 LSV 曲线. (n) Ni-Mo-N/CFC 电极上进行 $12 \mathrm{~h}$ 丙三醇氧化的 ${ }^{1} \mathrm{H} N \mathrm{NR}$ 谱. (o)丙三醇氧化为甲酸和甲醇. (p) Ni-Mo-N/CFC 在阳极发生丙三醇氧化反应前后 $\mathrm{Ni} 2 \mathrm{p}_{3 / 2}$ 的 XPS 谱

Figure 10 (a) SEM and (b, c) TEM images of Pt/Ni(OH) $/ 2$ rGO-4. (d) Representative scanning transmission X-ray microscopy mapping of Ni $\mathrm{L}_{3,2}$-edge intensity (red) over one rGO nanosheet suspended on lacy carbon support (green). Scale bars, $100 \mathrm{~nm}$ (a), $20 \mathrm{~nm}$ (b), 2nm (c) and (d). (e) Fourier transform EXAFS spectrum at the $\mathrm{Pt}_{3}$-edge. (f) $\mathrm{C}$ K-edge XANES spectrum. (g) $\mathrm{CV}$ curves in $1 \mathrm{~mol} \cdot \mathrm{L}^{-1} \mathrm{KOH}$ with $1 \mathrm{~mol} \cdot \mathrm{L}^{-1}$ methanol. (h) Short-term durability measurement. (i) SEM, (j) HRTEM images of Ni-Mo-N/CFC. (k) HRTEM images of the anodic post-GOR Ni-Mo-N/CFC. (1) Schematic illustration for concurrent electrolytic hydrogen and formate productions from glycerol solution. $(\mathrm{m}) \mathrm{LSV}$ curves of Ni-Mo-N/CFC anode in $1.0 \mathrm{~mol} \cdot \mathrm{L}^{-1} \mathrm{KOH}$ with and without $0.1 \mathrm{~mol} \cdot \mathrm{L}^{-1}$ glycerol addition. (n) ${ }^{1} \mathrm{H}$ NMR spectra of products before and after $12 \mathrm{~h}$ anodic glycerol oxidation on Ni-Mo-N/CFC electrode. (o) Glycerol consumption into formate and methanol. (p) High-resolution Ni $2 \mathrm{p}_{3 / 2}$ XPS spectra of Ni-Mo-N/CFC before and after glycerol oxidation at the anode 
其电化学活性物种无电催化活性, 会发生电化学析出现 象, 在保留相界面构成新异质结的情况下, 形成大量的 缺陷诱导暴露出丰富的电催化活性位点. 因此, 构建具 有活性型协同表界面的异质结可以优化异质结的活性 位点数, 改善其表面发生的电催化反应性能. 比如, 施 剑林课题组 ${ }^{[63]}$ 通过高温氮化在碳纤维布上生长的镍钼 化合物 NiMo-Pre/CFC, 获得了同时含金属 $\mathrm{Ni}$ 和 $\mathrm{Ni}_{0.2} \mathrm{Mo}_{0.8} \mathrm{~N}$ 的镍钼氮化物 (Ni-Mo-N/CFC) 纳米片 (图 $10 \mathrm{i} \sim 10 \mathrm{j}$ ). 电化学实验表明: Ni-Mo-N/CFC 作为阳极催 化剂时, 在 $0.1 \mathrm{~mol} \cdot \mathrm{L}^{-1}$ 丙三醇和 $1 \mathrm{~mol} \cdot \mathrm{L}^{-1} \mathrm{KOH}$ 溶液中 表现出了优异的电催化丙三醇氧化性能, 仅需 $1.30 \mathrm{~V}$ 电 压可响应出 $10 \mathrm{~mA} \cdot \mathrm{cm}^{-2}$ 的电流密度, 同时在阳极可将 丙三醇电氧化为高附加值的甲酸盐(图 $10 \mathrm{~m}$ 和 $10 \mathrm{n}$ ). 而 且, 可同时作为阳极和阴极电催化剂, 在丙三醇电转化 反应协同下, 促进水分解制氢(图 101). 在丙三醇电转化 为甲酸过程中, 检测到了甲醇的存在, 且在转移了约 $128 \mathrm{C}$ 电荷时甲醇与甲酸比例达到了 $1: 5$, 随后减少为 零(图 100). 通过同位素示踪研究了此过程, 结果表明伴 随甲醇产生的丙三醇氧化为甲酸过程是丙三醇氧化的 次要副反应, 其反应途径是丙三醇先氧化为丙酸脂, 然 后再氧化为甲酸. 采用 XPS 表征丙三醇氧化后的 Ni-Mo-N/CFC(Post-GOR Ni-Mo-N/CFC), 结果显示: 丙 三醇电氧化过程中, Ni-Mo-N/CFC 纳米片大部分的 $\mathrm{Ni}(0)$ 和 $\mathrm{Ni}(\mathrm{II})$ 被氧化为了 $\mathrm{NiOOH}$, 成为电氧化丙三醇 的活性位点(图 10p). 同时, 在阳极发生丙三醇氧化反应 后, $\mathrm{Mo}$ 被氧化为 $\mathrm{Mo}^{6+}$, 导致大量的 $\mathrm{Mo}$ 析出至电解液 中. Mo 损失导致该催化剂形成缺陷, 诱导暴露出更多的 活性位点并增强丙三醇电转化活性. 而且, Post-GOR $\mathrm{Ni}-\mathrm{Mo}-\mathrm{N} / \mathrm{CFC}$ 纳米片上仅含少量的金属 $\mathrm{Ni}$, 进一步表 明 Mo 不是丙三醇电转化反应的活性位点(图 10k). 因 此, 通过电催化活性和电化学活性的协同作用暴露出丰 富的电催化活性位点, 可以实现对生物质的高效电转 化.

\section{4 总结与展望}

近年来, 电催化生物质转化技术因具有大规模存储 间歇式能源和替代高污染、高能耗的工业化生产有机化 学品路线潜力受到了广泛的关注. 表界面化学工程因其 能有效改变电催化剂表面电子结构和几何结构的特点, 在二维材料电催化生物质转化领域取得了一系列进展. 在这篇综述中, 我们通过表界面化学工程调控二维材料 电催化生物质转化性能的实例介绍了四种表界面化学 工程: 即调控表面本征结构、构筑表面空位、引入表面 杂原子和构建表面协同界面. 通常, 这些表界面化学工 程调控二维材料后, 对提升电催化生物质转化性能有积 极作用. 其性能提升机理分别如下: 调控表面本征结构 是通过暴露特定晶面、优化边缘位点与面内位点比例、 引入晶格扭曲等策略, 选择性地暴露出高活度的活性位
点、增大活性位点数量和改善反应物分子在催化剂表面 的化学吸附能力; 构筑表面空位，是借助在表面产生的 阴离子空位、阳离子空位和纳米孔，增加配位不饱和的 活性位点, 改变空位位点邻域的电子结构和促进活性位 点暴露, 从而改善反应物分子在催化剂表面富集状态、 促进反应物分子的化学吸附和加速活性位点与吸附态 反应物之间的电子转移; 引入杂原子, 不仅可以利用非 金属杂原子调控其电子态诱导二维材料相变, 实现调节 活性位点的吸附能力和提高导电性，从而加快活性位点 与反应物及其中间体之间的电荷传输, 还可以通过引入 的金属杂原子与原始金属活性位点发生相互作用, 改变 其表面电子态，调节金属活性位点的生物质电转化能 力; 构建表面协同界面是通过具有不同的电子态或电化 学活性的两相协同作用, 改善对生物质分子的吸附能 力、诱导高活性位点的暴露和促进电荷转移及传输.

虽然表界面化学工程在调控二维材料的电催化生 物质转化性能上取得了一定的突破和成果, 但是仍然在 以下几个方面存在着挑战:

(1)目前还难以高选择性地实现生物质电转化产物 的多样化合成. 通过调控二维材料的表界面化学, 能够 有效提升其生物质电转化速率和抑制生物质电转化的 竞争反应发生, 进而提高生物质电转化选择性. 但是, 它对生物质电转化的产物选择性改善还存在明显不足. 比如, 乙醇的完全电催化氧化涉及到 $\mathrm{C}_{1}$ 和 $\mathrm{C}_{2}$ 产物, 具 有分别获得醛类、酮类、羧酸类产物的潜力 ${ }^{[7,93]}$, 目前 在乙醇电氧化反应中, 还难以通过调控二维材料表界面 化学分别有针对性和高选择性地获得单一特定产物, 从 而实现乙醇电转化产物的多样化合成.

(2)表界面化学调控二维材料生物质电转化机制还 需进一步深入关注. 例如, 肖特基异质界面的两侧分别 形成了亲核区和亲电区，对于生物质分子和中间体的吸 附分布目前尚不明确. 并且, 异质界面的大小、形状和 分布状态对选择性和效率的影响也值得重点关注. 杂原 子的引入, 改变了表面电子结构, 除了对吸附的影响, 对原始活性位点活化生物质反应路径的影响还需探索. 而且，虽然通过表界面化学工程对二维材料的表面电子 结构和几何结构调控, 实现了对生物质选择性活化, 但 是, 表界面化学如本征结构与生物质的选择性具体对应 关系仍然模糊不清. 通过详细研究催化剂中不同表界面 化学工程调控所起的作用, 对于开发出具有高效生物质 电转化活性和选择性的二维电催化剂具有重要意义.

(3)在表征表界面化学调控后的二维材料和生物质 电转化过程中表界面化学调控所扮演的作用中, 还缺乏 先进的表征技术. 目前虽然借助 XAFs，XPS，ESR 能表 征出表面空位缺陷，并且发现表面空位的存在能提升电 催化的活性，但表面空位缺陷的种类、含量以及所在的 局域原子环境还难以明晰. 另外，尽管理论计算是研究 催化模型和性能之间关系的有效手段，但目前建立的催 化模型还不能反映催化剂在电催化过程中的真实状态. 
因此，应开发先进的表征技术，尤其是原位光谱技术， 例如, 在电催化条件下进行原位傅里叶变换红外光谱和 原位 Raman 测试, 以监测电解质/反应物/催化剂/中间 体, 理解电催化过程中的活性位点和催化机理.

通过对表界面化学工程调控机理的深入理解, 能更 加合理地设计出高效、高选择性、长时间稳定的电催化 生物质转化的二维电催化材料. 随后, 有望利用间歇式 能源驱动工业化大规模制氢和生物质合成高附加值工 业化学品, 实现对能源结构的优化, 降低对化石能源的 依赖，减缓温室效应和环境污染等环境问题.

\section{作者简介}

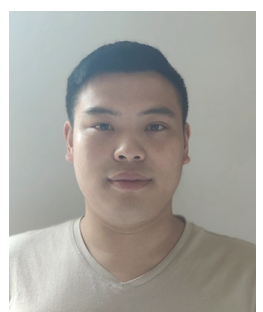

王文樹, 2017 年在南京师范大学获学士学位, 现在在华中 科技大学翟天佑教授和刘友文副教授的指导下攻读博士学位. 主要研究方向是二维过渡金属基材料电催化小分子转化在能 源转化和存储领域的应用.

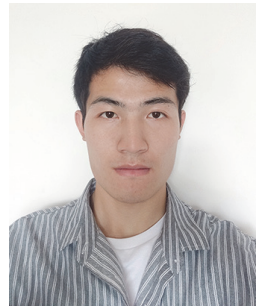

温群否, 2018 年在华中科技大学获学士学位, 现在在华中 科技大学翟天佑教授、刘友文副教授指导下攻读博士学位, 主 要研究方向为能源转换与催化材料.

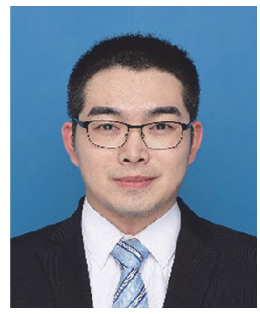

刘友文, 博士, 副教授, 博士生导师, 2017 年毕业于中国 科学技术大学无机化学专业, 获得博士学位, 同年加入华中 科技大学材料科学与工程学院. 主要研究方向: 二维电催化 材料与器件.

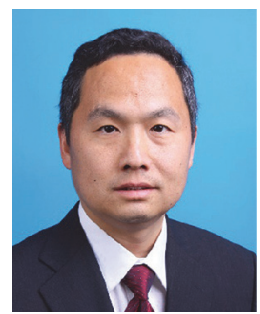

翟天佑, 博士, 教授, 博士生导师, 2008 年获得中国科学
院化学研究所博士学位. $2008 \sim 2012$ 年在日本物质材料研究 机构先后任 JSPS 博士后和 ICYS 研究员, 现任华中科技大学 材料科学与工程学院首席教授. 主要研究领域为无机功能纳 米材料的可控合成和其物理性质探索, 以及在能源、电子、光 子领域中的应用.

\section{References}

[1] Luna, P. D.; Hahn, C.; Higgins, D.; Jaffer, S. A.; Jaramillo, T. F.; Sargent, E. H. Science 2019, 364, eaav3506.

[2] Seh, Z. W.; Kibsgaard, J.; Dickens, C. F.; Chorkendorff, I.; Norskov, J. K.; Jaramillo, T. F. Science 2017, 355, eaad4998.

[3] Du, L.; Shao, Y.; Sun, J.; Yin, G.; Du, C.; Wang, Y. Catal. Sci. Technol. 2018, $8,3216$.

[4] Li, Z.; Luo, Y.; Jiang, Z.; Fang, Q.; Hu, C. Chin. J. Chem. 2020, 38, 178.

[5] Li, C.; Zhang, Q.; Fu, Y. Acta Chim. Sinica. 2018, 76, 501. (李翠, 张琪，傅尧，化学学报, 2018, 76, 501.)

[6] Liu, R. Y.; Bae, M.; Buchwald, S. L. J. Am. Chem. Soc. 2018, 140, 1627.

[7] Sun, J.; Wang, Y. ACS Catal. 2014, 4, 1078.

[8] Chen, Y.; Liu, H.; Cheng, Y.; Xie, Q. Acta Chim. Sinica. 2020, 78, 330. (陈莹莹, 刘欢, 程彦, 谢青季, 化学学报, 2020, 78, 330.)

[9] Liao, G.; Wu, Y.-J.; Shi, B.-F. Acta Chim. Sinica. 2020, 78, 289. (廖 港, 吴勇杰, 史炳锋,化学学报, 2020, 78, 289.)

[10] Li, W.; Jiang, N.; Hu, B.; Liu, X.; Song, F.; Han, G.; Jordan, T. J.; Hanson, T. B.; Liu, T. L.; Sun, Y. Chem 2018, 4, 637.

[11] Lu, F.; Yang, Z.; Wang, T.; Wang, T.; Zhang, Y.; Yuan, Y.; Lei, A. Chin. J. Chem. 2019, 37, 547.

[12] You, B.; Liu, X.; Jiang, N.; Sun, Y. J. Am. Chem. Soc. 2016, 138 13639.

[13] Chi, J.; Yu, H. Chin. J. Catal. 2018, 39, 390. (迟军, 俞红梅, 催化 学报, 2018, 39, 390.)

[14] Cheng, P.-F.; Feng, T.; Liu, Z.-W.; Wu, D.-Y.; Yang, J. Chin. J. Catal. 2019, 40, 1147. (程鹏飞, 冯婷, 刘紫薇, 吴德圭, 杨静, 催 化学报, 2019, 40, 1147.)

[15] Hang-shuo, L.; Xiao-bo, H.; Feng-xiang, Y.; Guo-ru, L. J. Electrochem. 2020, 26, 136. (陆杭炼, 何小波, 银凤翔, 李国儒, 电化学, 2020, 26, 136.)

[16] You, H.; Zhuo, Z.; Lu, X.; Liu, Y.; Guo, Y.; Wang, W.; Yang, H.; Wu, X.; Li, H.; Zhai, T. CCS Chem. 2019, 1, 396.

[17] Montoya, J. H.; Seitz, L. C.; Chakthranont, P.; Vojvodic, A.; Jaramillo, T. F.; Norskov, J. K. Nat. Mater. 2016, 16, 70.

[18] Zhang, P.; Sun, L. Chin. J. Chem. 2020, 38, 996.

[19] Liu, Y.; Xiao, C.; Huang, P.; Cheng, M.; Xie, Y. Chem 2018, 4, 1263.

[20] Liu, Y.; Hua, X.; Xiao, C.; Zhou, T.; Huang, P.; Guo, Z.; Pan, B.; Xie, Y. J. Am. Chem. Soc. 2016, 138, 5087.

[21] Zhu, W.; Ren, M.; Hu, N.; Zhang, W.; Luo, Z.; Wang, R.; Wang, J.; Huang, L.; Suo, Y.; Wang, J. ACS Sustainable Chem. Eng. 2018, 6 5011.

[22] Li, Y.; Lu, J.; Wang, X.; Zhang, H.; Wu, X.; Zhang, K. H. L.; Ye, J.; Zhan, D. Chem CatChem 2019, 11, 2277.

[23] Ojha, K.; Farber, E. M.; Burshtein, T. Y.; Eisenberg, D. Angew. Chem. Int. Ed. 2018, 57, 17168.

[24] Wang, Z.; Xu, L.; Huang, F.; Qu, L.; Li, J.; Owusu, K. A.; Liu, Z.; Lin, Z.; Xiang, B.; Liu, X.; Zhao, K.; Liao, X.; Yang, W.; Cheng, Y.-B.; Mai, L. Adv. Energy Mater. 2019, 9, 1900390.

[25] Yang, W.; Yang, X.; Jia, J.; Hou, C.; Gao, H.; Mao, Y.; Wang, C.; Lin, J.; Luo, X. App. Catal. B: Environ. 2019, 244, 1096.

[26] Yang, W.; Yang, X.; Hou, C.; Li, B.; Gao, H.; Lin, J.; Luo, X. App. Catal. B: Environ. 2019, 259, 118020.

[27] Wang, W.; Zhu, Y.-B.; Wen, Q.; Wang, Y.; Xia, J.; Li, C.; Chen, M.-W.; Liu, Y.; Li, H.; Wu, H.-A.; Zhai, T. Adv. Mater. 2019, 31, 1900528.

[28] Zhu, X.; Dou, X.; Dai, J.; An, X.; Guo, Y.; Zhang, L.; Tao, S.; Zhao, J.; Chu, W.; Zeng, X. C.; Wu, C.; Xie, Y. Angew. Chem. Int. Ed. 2016, 55, 12465.

[29] Li, K.; Sun, Y. Chem. Eur. J. 2018, 24, 18258.

[30] Chen, L.; Shi, J. J. Mater. Chem. A. 2018, 6, 13538.

[31] Yu, Z.-Y.; Lang, C.-C.; Gao, M.-R.; Chen, Y.; Fu, Q.-Q.; Duan, Y.; Yu, S.-H. Energy Environ. Sci. 2018, 11, 1890.

[32] Boggs, B. K.; King, R. L.; Botte, G. G. Chem. Commun. 2009, 32, 4859 . 
[33] Chen, S.; Duan, J.; Vasileff, A.; Qiao, S. Z. Angew. Chem. Int. Ed. 2016, 55, 3804.

[34] Li, C.; Liu, Y.; Zhuo, Z.; Ju, H.; Li, D.; Guo, Y.; Wu, X.; Li, H.; Zhai, T. Adv. Energy Mater. 2018, 8, 1801775.

[35] Tang, C.; Zhang, R.; Lu, W.; Wang, Z.; Liu, D.; Hao, S.; Du, G.; Asiri, A. M.; Sun, X. Angew. Chem. Int. Ed. 2017, 56, 842.

[36] Wu, L.-S.; Dai, H.-B.; Wen, X.-P.; Wang, P. ChemElectroChem 2017, 4, 1944.

[37] Ma, X.; Wang, J.; Liu, D.; Kong, R.; Hao, S.; Du, G.; Asiri, A. M.; Sun, X. New J. Chem. 2017, 41, 4754.

[38] Wang, Y.; Chen, Z.; Wu, H.; Xiao, F.; Cao, E.; Du, S.; Wu, Y.; Ren, Z. ACS Sustainable Chem. Eng. 2018, 6, 15727.

[39] Liu, M.; Zhang, R.; Zhang, L.; Liu, D.; Hao, S.; Du, G.; Asiri, A. M.; Kong, R.; Sun, X. Inorg. Chem. Front. 2017, 4, 420.

[40] Sun, H.; Ye, Y.; Liu, J.; Tian, Z.; Cai, Y.; Li, P.; Liang, C. Chem. Commun. 2018, 54, 1563.

[41] Chen, G.-F.; Luo, Y.; Ding, L.-X.; Wang, H. ACS Catal. 2017, 8, 526.

[42] Fu, W.; Li, Y.; Liang, C. Acta Chim. Sinica. 2019, 77, 559. (付雯雯, 李严, 梁长海, 化学学报, 2019, 77, 559.)

[43] Wu, K.; Zhou, Y.; Ma, X.; Ding, C.; Cai, W. Acta Chim. Sinica. 2018, 76, 292. (吴匡衡, 周亚威, 马宪印, 丁辰, 蔡文斌, 化学学 报, 2018, 76, 292.)

[44] Lam, C. H.; Bloomfield, A. J.; Anastas, P. T. Green Chem. 2017, 19, 1958.

[45] Bott-Neto, J. L.; Martins, T. S.; Machado, S. r. A. S.; Ticianelli, E. A. ACS Appl. Mater. Interfaces 2019, 11, 30810.

[46] You, B.; Liu, X.; Liu, X.; Sun, Y. ACS Catal. 2017, 7, 4564

[47] Yin, Z.; Zheng, Y.; Wang, H.; Li, J.; Zhu, Q.; Wang, Y.; Ma, N.; Hu, G.; He, B.; Knop-Gericke, A.; Schlogl, R.; Ma, D. ACS Nano 2017, $11,12365$.

[48] Zheng, J.; Chen, X.; Zhong, X.; Li, S.; Liu, T.; Zhuang, G.; Li, X.; Deng, S.; Mei, D.; Wang, J.-G. Adv. Funct. Mater. 2017, 27, 1704169.

[49] Zhang, X.; Han, M.; Liu, G.; Wang, G.; Zhang, Y.; Zhang, H.; Zhao, H. App. Catal. B: Environ. 2019, 244, 899.

[50] Nam, D.-H.; Taitt, B. J.; Choi, K.-S. ACS Catal. 2018, 8, 1197.

[51] Liu, W.-J.; Dang, L.; Xu, Z.; Yu, H.-Q.; Jin, S.; Huber, G. W. $A C S$ Catal. 2018, $8,5533$.

[52] Du, P.; Zhang, J.; Liu, Y.; Huang, M. Electrochem. Commun. 2017, $83,11$.

[53] Liu, W. J.; Xu, Z.; Zhao, D.; Pan, X. Q.; Li, H. C.; Hu, X.; Fan, Z. Y.; Wang, W. K.; Zhao, G. H.; Jin, S.; Huber, G. W.; Yu, H. Q. Nat. Commun. 2020, 11, 265.

[54] Miao, J.; Teng, X.; Zhang, R.; Guo, P.; Chen, Y.; Zhou, X.; Wang, H.; Sun, X.; Zhang, L. App. Catal. B: Environ. 2020, 263, 118109.

[55] Ding, Y.; Miao, B.-Q.; Li, S.-N.; Jiang, Y.-C.; Liu, Y.-Y.; Yao, H.-C.; Chen, Y. App. Catal. B: Environ. 2020, 268, 118393.

[56] Huang, Y.; Chong, X.; Liu, C.; Liang, Y.; Zhang, B. Angew. Chem. Int. Ed. 2018, 57, 13163.

[57] Lum, Y.; Huang, J. E.; Wang, Z.; Luo, M.; Nam, D.-H.; Leow, W. R.; Chen, B.; Wicks, J.; Li, Y. C.; Wang, Y.; Dinh, C.-T.; Li, J.; Zhuang, T.-T.; Li, F.; Sham, T.-K.; Sinton, D.; Sargent, E. H. Nat. Catal. 2020, 3, 14.

[58] Zhou, Y.; Gao, Y.; Zhong, X.; Jiang, W.; Liang, Y.; Niu, P.; Li, M.; Zhuang, G.; Li, X.; Wang, J. Adv. Funct. Mater. 2019, 29, 1807651.

[59] Zhang, B.; Huang, C.; Huang, Y.; Liu, C.; Chong, X. Natl. Sci. Rev. 2020, 7, 285.

[60] Liu, C.; Hirohara, M.; Maekawa, T.; Chang, R.; Hayashi, T.; Chiang, C.-Y. App. Catal. B: Environ. 2020, 265, 118543.

[61] Dai, L.; Qin, Q.; Zhao, X.; Xu, C.; Hu, C.; Mo, S.; Wang, Y. O.; Lin, S.; Tang, Z.; Zheng, N. ACS Cent. Sci. 2016, 2, 538.

[62] Zhang, N.; Zou, Y.; Tao, L.; Chen, W.; Zhou, L.; Liu, Z.; Zhou, B.; Huang, G.; Lin, H.; Wang, S. Angew. Chem. Int. Ed. 2019, 58, 15895.

[63] Li, Y.; Wei, X.; Chen, L.; Shi, J.; He, M. Nat. Commun. 2019, 10, 5335.

[64] Dai, H.; Wu, F.; Bai, D. Chin. J. Org. Chem. 2020, 40, 1423. (代洪 雪, 吴 芬, 白大昌, 有机化学, 2020, 40, 1423.)

[65] Li, Y.; Jiang, Y.; Jiang, P.; Du, S.; Jiang, J.; Leng, Y. Acta Chim. Sinica. 2019, 77, 66. (李月, 姜宇晨, 蒋平平, 杜盛郁, 姜就胜, 冷 炎, 化学学报, 2019, 77, 66.)

[66] Zhai, Y.; Xu, W.; Meng, X.; Hou, H. Acta Chim. Sinica. 2020, 78,
256. (翟亚丽，许文娟，孟祥茹，侯红卫，化学学报，2020，78， 256.)

[67] Zhang, Y.; Duan, H.-X.; Wang, Y.-Q. Chin. J. Org. Chem. 2020, 40, 1514. (张永娜, 段慧欣, 汪游清, 有机化学, 2020, 40,1514.)

[68] Zhang, B.; Zheng, X.; Voznyy, O.; Comin, R.; Bajdich, M.; García-Melchor, M.; Han, L.; Xu, J.; Liu, M.; Zheng, L.; Arquer, F. P. G. d.; Dinh, C. T.; Fan, F.; Yuan, M.; Yassitepe, E.; Chen, N.; Regier, T.; Liu, P.; Li, Y.; Luna, P. D.; Janmohamed, A.; Xin, H. L.; Yang, H.; Vojvodic, A.; Sargent, E. H. Science 2016, 352, 333.

[69] Tan, C.; Luo, Z.; Chaturvedi, A.; Cai, Y.; Du, Y.; Gong, Y.; Huang, Y.; Lai, Z.; Zhang, X.; Zheng, L.; Qi, X.; Goh, M. H.; Wang, J.; Han, S.; Wu, X. J.; Gu, L.; Kloc, C.; Zhang, H. Adv. Mater. 2018, 30, 1705509.

[70] Burke, M. S.; Kast, M. G.; Trotochaud, L.; Smith, A. M.; Boettcher, S. W. J. Am. Chem. Soc. 2015, 137, 3638

[71] Zhang, J. Y.; Wang, H.; Tian, Y.; Yan, Y.; Xue, Q.; He, T.; Liu, H.; Wang, C.; Chen, Y.; Xia, B. Y. Angew. Chem. Int. Ed. 2018, 57, 7649 .

[72] Gao, Y.; Wang, Q.; He, T.; Zhang, J.-Y.; Sun, H.; Zhao, B.; Xia, B. Y.; Yan, Y.; Chen, Y. Inorg. Chem. Front. 2019, 6, 2686.

[73] Liu, R.; Wang, Y.; Liu, D.; Zou, Y.; Wang, S. Adv. Mater. 2017, 29, 1701546

[74] Jia, X.; Zhang, X.; Zhao, J.; Zhao, Y.; Zhao, Y.; Waterhouse, G. I. N.; Shi, R.; Wu, L.-Z.; Tung, C.-H.; Zhang, T. J. Energy Chem. 2019, $34,57$.

[75] Dou, S.; Tao, L.; Wang, R.; El Hankari, S.; Chen, R.; Wang, S. Adv. Mater. 2018, 30, 1705850.

[76] Chen, X.; Liu, L.; Yu, P. Y.; Mao, S. S. Science 2011, 331, 746.

[77] Yin, Y.; Han, J.; Zhang, Y.; Zhang, X.; Xu, P.; Yuan, Q.; Samad, L.; Wang, X.; Wang, Y.; Zhang, Z.; Zhang, P.; Cao, X.; Song, B.; Jin, S. J. Am. Chem. Soc. 2016, 138, 7965 .

[78] He, Q.; Wan, Y.; Jiang, H.; Pan, Z.; Wu, C.; Wang, M.; Wu, X.; Ye, B.; Ajayan, P. M.; Song, L. ACS Energy Lett. 2018, 3, 1373.

[79] Zhang, L.; Wang, L.; Lin, H.; Liu, Y.; Ye, J.; Wen, Y.; Chen, A.; Wang, L.; Ni, F.; Zhou, Z.; Sun, S.; Li, Y.; Zhang, B.; Peng, H. Angew. Chem. Int. Ed. 2019, 58, 16820.

[80] Zhang, X.; Zhao, Y.; Zhao, Y.; Shi, R.; Waterhouse, G. I. N.; Zhang, T. Adv. Energy Mater. 2019, 9, 1900881.

[81] Wang, W.; Wang, Y.; Yang, R.; Wen, Q.; Liu, Y.; Jiang, Z.; Li, H.; Zhai, T. Angew. Chem. Int. Ed. 2020, 59, 16974.

[82] Zhao, Y.; Zhang, X.; Jia, X.; Waterhouse, G. I. N.; Shi, R.; Zhang, X.; Zhan, F.; Tao, Y.; Wu, L.-Z.; Tung, C.-H.; O'Hare, D.; Zhang, T. Adv. Energy Mater. 2018, 8, 1703585.

[83] Yang, P. P.; Zhang, X. L.; Gao, F. Y.; Zheng, Y. R.; Niu, Z. Z.; Yu, X.; Liu, R.; Wu, Z. Z.; Qin, S.; Chi, L. P.; Duan, Y.; Ma, T.; Zheng, X. S.; Zhu, J. F.; Wang, H. J.; Gao, M. R.; Yu, S. H. J. Am. Chem. Soc. 2020, 142, 6400

[84] Du, C. F.; Sun, X.; Yu, H.; Fang, W.; Jing, Y.; Wang, Y.; Li, S.; Liu, X.; Yan, Q. InfoMat. 2020, 2, 950.

[85] Wu, Y.; Liu, X.; Han, D.; Song, X.; Shi, L.; Song, Y.; Niu, S.; Xie, Y.; Cai, J.; Wu, S.; Kang, J.; Zhou, J.; Chen, Z.; Zheng, X.; Xiao, X.; Wang, G. Nat.Commun. 2018, 9, 1425.

[86] Dong, B.; Li, W.; Huang, X.; Ali, Z.; Zhang, T.; Yang, Z.; Hou, Y. Nano Energy 2019, 55, 37.

[87] Liu, T.; Liu, D.; Qu, F.; Wang, D.; Zhang, L.; Ge, R.; Hao, S.; Ma, Y.; Du, G.; Asiri, A. M.; Chen, L.; Sun, X. Adv. Energy Mater. 2017, 7, 1700020 .

[88] Dai, M.; Wang, J.; Li, L.; Wang, Q.; Liu, M.; Zhang, Y. Acta Chim. Sinica. 2020, 78, 355. (代迷迷, 王健, 李麟阁, 王琪, 刘美男, 张 跃钢, 化学学报, 2020, 78, 355.)

[89] Wang, C.; Lu, H.; Mao, Z.; Yan, C.; Shen, G.; Wang, X. Adv. Funct. Mater. 2020, 30, 2000556.

[90] Huang, W.; Ma, X. Y.; Wang, H.; Feng, R.; Zhou, J.; Duchesne, P. N.; Zhang, P.; Chen, F.; Han, N.; Zhao, F.; Zhou, J.; Cai, W. B.; Li, Y. Adv. Mater. 2017, 29, 1703057

[91] Han, Y.; Li, P.; Liu, J.; Wu, S.; Ye, Y.; Tian, Z.; Liang, C. Sci. Rep. 2018, 8, 1359.

[92] Huang, W.; Wang, H.; Zhou, J.; Wang, J.; Duchesne, P. N.; Muir, D.; Zhang, P.; Han, N.; Zhao, F.; Zeng, M.; Zhong, J.; Jin, C.; Li, Y.; Lee, S. T.; Dai, H. Nat. Commun. 2015, 6, 10035.

[93] Yue, X.; Li, L.; Li, P.; Luo, C.; Pu, M.; Yang, Z.; Lei, M. Chin. J. Chem. 2019, 37, 883 .

(Cheng, B.) 